\title{
Efficacy, biocompatibility and degradability of carbon nanoparticles for photothermal therapy of lung cancer
}

\author{
Ida Kokalari1 (iD), Sandeep Keshavan² (D), Mizanur Rahman² (D), Elena Gazzano(iD, Giulia

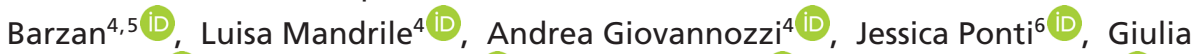 \\ Antonello $^{1 \text { (D) }}$, Marco Monopoli ${ }^{7}$ (D) Guido Perrone ${ }^{8}$ iD) Enrico Bergamaschi ${ }^{9}$ (D) Chiara \\ Riganti $^{10}$ (D) Bengt Fadeel*,2 (D) \& Ivana Fenoglio**,1 (iD) \\ ${ }^{1}$ Department of Chemistry, University of Torino, 10125, Torino, Italy \\ ${ }^{2}$ Division of Molecular Toxicology, Institute of Environmental Medicine, Karolinska Institutet, 17177, Stockholm, Sweden \\ ${ }^{3}$ Department of Life Sciences \& Systems Biology, University of Torino, 10123, Torino, Italy \\ ${ }^{4}$ National Institute of Metrological Research (INRiM), 10135, Torino, Italy \\ ${ }^{5}$ Department of Electronics andTelecommunications, Politecnico di Torino, 10129, Turin, Italy \\ ${ }^{6}$ EuropeanCommission, Joint Research Centre (JRC), 21027, Ispra (VA), Italy \\ ${ }^{7}$ Department of Chemistry, Royal College of Surgeons in Ireland (RCSI), Dublin 2, Ireland \\ ${ }^{8}$ Department of Electronics \& Telecommunications, Polytechnic of Torino, 10129, Torino, Italy \\ ${ }^{9}$ Department of Public Health \& Pediatrics, University of Torino, 10126, Torino, Italy \\ ${ }^{10}$ Department of Oncology, University of Torino, 10126, Torino, Italy \\ *Author for correspondence: Tel.: +46 8524877 37; bengt.fadeel@ki.se \\ **Author for correspondence: Tel.: +39 11 6707506; ivana.fenoglio@unito.it
}

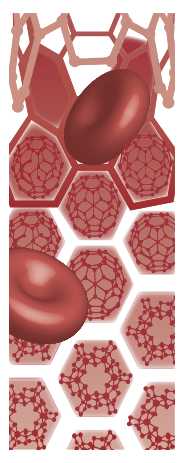

Aim: To investigate near infrared-induced phototoxicity toward lung cancer cells, and the biodegradability and effect on immune cells of glucose-derived carbon nanoparticles (CNPs). Methods: The human A549 lung adenocarcinoma cell line was used as a model to study the phototoxicity of CNPs. The biodegradability and the effect on immune cells was demonstrated in primary human neutrophils and macrophages. Results: Near infrared-activated CNPs elicited rapid cell death, characterized by the elevation of heat shock proteins and the induction of DNA damage. CNPs were found to be noncytotoxic toward primary human macrophages and were susceptible to biodegradation when cocultured with human neutrophils. Conclusions: Our results identify CNPs as promising platforms for photothermal therapy of lung cancer.

Graphical abstract:

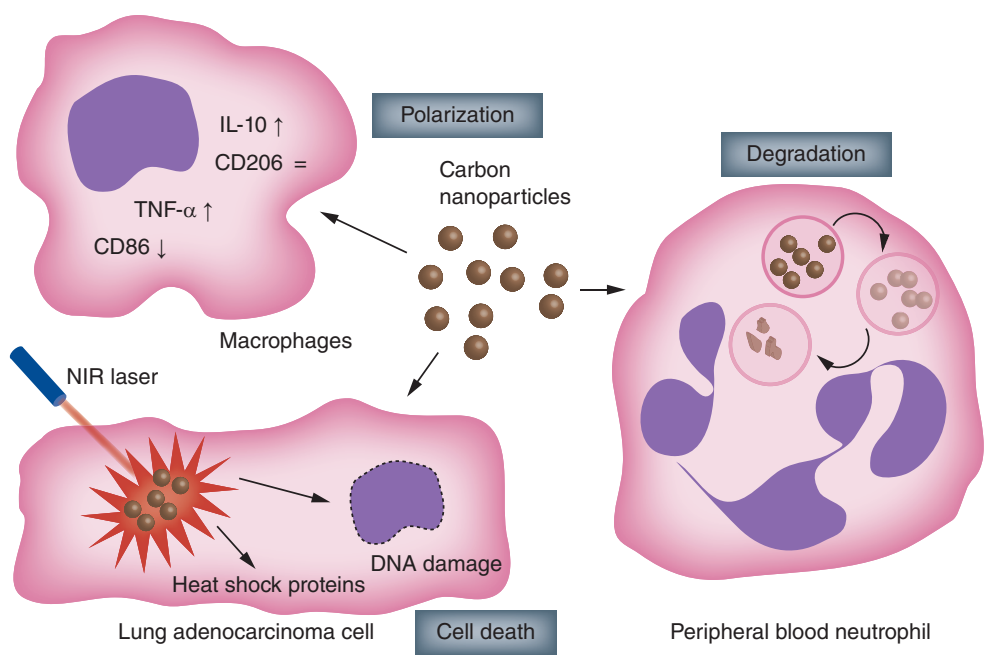

First draft submitted: 8 January 2021; Accepted for publication: 17 March 2021; Published online: 14 April 2021

Keywords: biodegradation • carbon-based nanomaterials • immune cells • lung cancer $\bullet$ photothermal therapy 
Lung cancer is the leading cause of cancer-related death worldwide [1]. Various treatments have been employed in lung cancer therapy, including surgery, radiotherapy, chemotherapy and immunotherapy, either alone or in combination [2]. Non-small-cell lung cancers (NSCLCs) represent approximately $85 \%$ of all lung cancers; however, only $25-30 \%$ of patients are candidates for surgery [3]. In addition, lung cancer resection is associated with a low survival rate, except in patients with early-stage disease [4]. On the other hand, chemotherapy for lung cancers is still associated with poor outcome due to low selectivity, insufficient drug concentration in the tumor and the frequent development of multidrug resistance [5]. Thus new therapeutic approaches for a more efficacious treatment are urgently needed.

Phototherapies have gained attention as an alternative to conventional treatments in recent years. Moreover, several studies report that phototherapies can be combined with other therapeutic modalities to enhance the efficacy $[6,7]$. In order to improve the potency and selectivity of phototherapies, a variety of light-responsive molecular agents, like porphyrins or photoactive nanoparticles, have been developed. These agents can be administered via direct intratumoral injection or by parenteral administration, applying appropriate active or passive targeting strategies. Phototherapy can be divided in two main categories: photothermal therapy (PTT) and photodynamic therapy (PDT). PTT agents are able to convert electromagnetic energy to intense heat [6] and can find application in hyperthermia or laser ablation of tumors [8] PDT consists of the administration of molecules or nanoparticles that transfer absorbed electromagnetic energy to oxygen molecules, generating cytotoxic reactive oxygen species (ROS) [9]. PDT treatment based on molecular photosensitizers is already approved for the treatment of NSCLC [10]. The most commonly used photosensitizer is porfimer sodium (Photofrin ${ }^{\circledR}$ ), which was introduced more than a decade ago [11]. Among the different light-responsive nanomaterials, carbon-based nanomaterials (CNMs), such as single-walled carbon nanotubes [12,13], fullerenes [14] and graphene [15] have been proposed for both PTT and PDT. However, their translation to the clinic faces several challenges related to their production, such as the expensive synthetic methods, time-consuming purification procedures and low batch-to-batch reproducibility. Moreover, CNMs tend to aggregate due to strong van der Waal interactions because of their hydrophobic properties. Therefore they must be functionalized to enable dispersion in aqueous media, further reducing the yield of the final product. Like all nanomaterials intended for clinical use, CNMs must also be subjected to thorough assessment of their biocompatibility [16].

Polysaccharide-derived carbon nanoparticles (CNPs) are an emerging class of CNMs [17]. They consist mainly of amorphous carbon, but exhibit graphitic domains embedded in the amorphous matrix. Compared with other CNMs, they can be produced in high yield and their size can be easily tuned [18]. Moreover, they exhibit a functionalized surface that makes them stable and negatively charged in water and allows functionalization. Some studies have proposed CNPs as drug delivery agents [19-21]. Recently, Miao et al. reported that saccharide-derived CNPs exhibit photoacoustic and photothermal properties when irradiated by near-infrared (NIR) light [22]. We recently reported the synthesis of tailored glucose-derived graphitic CNPs with a diameter of $80 \mathrm{~nm}$ that possess the ability to generate singlet oxygen and heat upon NIR irradiation in cell-free tests [18]. These CNPs were shown to be noncytotoxic toward a murine macrophage cell line and significant antioxidant activity was observed, as a consequence of their ability to scavenge hydroxyl radicals. Finally, in a subsequent study CNPs were shown to remain stable in human plasma and blood, implying good hematocompatibility [23].

Here we investigated the efficiency of CNPs to induce cell death in human NSCLC cells when activated by NIR irradiation. Moreover, we explored the biocompatibility of CNPs toward primary human macrophages and neutrophils, as well as the susceptibility of CNPs to undergo enzymatic degradation by neutrophils.

\section{Materials \& methods}

Synthesis \& sterilization of CNPs

CNPs were obtained by hydrothermal carbonization following a previously optimized protocol [18], without modifications. Briefly, $2 \mathrm{~g}$ of glucose were dissolved in $50 \mathrm{ml}$ of ultrapure water and subsequently $15 \mathrm{mg}$ of sodium polyacrylate were added. The solution was placed in a stainless-steel miniclave, equipped with a PTFE insert (100 ml, Büchi AG, Uster, Switzerland) and heated for $3 \mathrm{~h}$ at $190^{\circ} \mathrm{C}$. The suspension was then purified by tangential ultrafiltration (Vivaflow 50R cassettes, Sartorius, Goettingen, Germany, $30 \mathrm{kDa}$ cutoff) using ultrapure water (Millipore, Merck, Darmstadt, Germany). For sterilization, the CNP suspension was introduced into an autoclave and sterilized at $121^{\circ} \mathrm{C}$ for $30 \mathrm{~min}$. One aliquot of the suspension was stored at $4^{\circ} \mathrm{C}$ and used as a 
control for comparison with the sterilized sample in terms of hydrodynamic diameter, $\zeta$-potential (using Zetasizer Nano, Malvern Instruments, Malvern, UK) and pH. Samples were also subjected to thermogravimetric analysis, as previously described [18], to detect changes in internal structure due to the high temperature during sterilization. Sterilization was further confirmed by the absence of bacterial contamination in the agar plate test based on a protocol developed by the European Nanomedicine Characterization Laboratory [24]. To this end, CNP samples and controls (ultrapure water in the case of negative control, and Escherichia coli MG1655, $5 \times 10^{2}$ colony-forming units $/ \mathrm{ml}$, in the case of positive control) were spread on agar and the growth of bacterial colonies was monitored after $72 \mathrm{~h}$ of incubation at $37^{\circ} \mathrm{C}$.

\section{Characterization of CNPs}

Fourier transformed infrared analysis

Attenuated total reflection Fourier transformed infrared (FTIR) measurements were performed on a ThermoFisher Nicolet iS10 instrument (Waltham, MA, USA). Spectra were obtained from 16 scans with a resolution of $4 \mathrm{~cm}^{-1}$ in the spectral region of $650-4000 \mathrm{~cm}^{-1}$. CNP suspensions were lyophilized, and aliquots were analyzed without prior preparation.

\section{Dynamic light scattering \& electrophoretic light scattering}

The $\zeta$-potential and hydrodynamic diameter were evaluated by using electrophoretic light scattering and dynamic light scattering, respectively (Zetasizer Nano). The CNPs were suspended $(1 \mathrm{mg} / \mathrm{ml})$ in ultrapure water, sonicated (Bandelin Sonopuls HD 3100, Berlin, Germany) and then diluted 1:5 in ultrapure water. Three independent replicates were performed for each condition. The results were expressed as $\zeta$-potential, hydrodynamic diameter distribution (average of mean values of ten measurements obtained in three independent experiments), mean hydrodynamic diameter (Z-average diameter) and polydispersity index.

\section{Scanning \& transmission electron microscopy}

CNP morphology was characterized by scanning electron microscopy (SEM) (Quanta ${ }^{T M}$ 3D FEG DualBeam ${ }^{T M}$, FEI company, Hillsboro, OR, USA). CNP suspensions were diluted in ultrapure water at a final concentration of $0.02 \mathrm{mg} / \mathrm{ml}$. The diluted suspension was deposited on aluminum stubs equipped with silicon wafers and airdried. Nanoparticle morphology analysis was performed at an acceleration voltage of $10 \mathrm{kV}$. For high-resolution transmission electron microscopy (TEM), micrographs were achieved with a 3010 Jeol instrument (Akishima, Tokyo) operating at $300 \mathrm{kV}$. An aqueous CNP suspension $(0.05 \mathrm{mg} / \mathrm{ml})$ was dropped on a copper grid covered with a lacey carbon film.

\section{Stability of CNPs in cell culture media}

CNP stock suspension with a concentration of $1 \mathrm{mg} / \mathrm{ml}$ was sonicated for $30 \mathrm{~min}$ in a bath sonicator followed by vortexing to obtain a homogeneous dispersion. Aliquots of $1 \mathrm{ml}$ were taken and sonicated with a probe sonicator (Bandelin Sonopuls HD 3100, Ti probe diameter $3 \mathrm{~mm}$, power $400 \mathrm{~W}$, frequency $20 \mathrm{kHz}$ ) for 2 min using the pulsation mode at $40 \%$ of power. The final suspension was then diluted in cell culture medium (RPMI-1640) supplemented with $10 \%$ fetal bovine serum (FBS). Stability was evaluated at 0, 3, 6 and 24 h to mimic the conditions of the cytotoxicity tests using primary immune cells. In the case of A549 cells, the stability was studied in Ham's F12 medium supplemented with 10\% FBS at 0, 24 and 48 h of incubation. The hydrodynamic diameter distribution was evaluated by dynamic light scattering as described above. Instrument setting: replicates 10, delay time 0 , equilibrium time $5 \mathrm{~min}, \mathrm{~T}=25^{\circ} \mathrm{C}$, dispersant refractive index and viscosity $1.330 / 0.8882 \mathrm{mPa}$ (cell media); material refractive index and absorption: $2.4204 / 1.000$.

\section{Lung cell line culture \& exposure}

The human A549 lung adenocarcinoma cell line, provided by Istituto Zooprofilattico Sperimentale 'Bruno Ubertini’ (Brescia, Italy), was cultured in Ham's F12 medium (Invitrogen Life Technologies, CA, USA) supplemented with 10\% FBS (Invitrogen Life Technologies) and 1\% penicillin/streptomycin. The human NCI-H1650 lung adenocarcinoma cell line and the human bronchial epithelial BEAS-2B cell line, provided by the American Type Culture Collection (VA, USA), were cultured in RPMI-1640 medium (Invitrogen Life Technologies), supplemented with 10\% FBS and 1\% penicillin/streptomycin. In all experiments, an aliquot of the CNP suspension was collected from the stock $(1 \mathrm{mg} / \mathrm{ml})$ after bath sonication for $30 \mathrm{~min}$ and transferred into a 2-ml tube; before incubation with cells, the suspension was sonicated again with a probe sonicator (Bandelin Sonopuls HD 3100) for 2 min using the pulsation mode at $40 \%$ of power. 


\section{Cytotoxicity \& cellular uptake Cytotoxicity}

The CNP suspension, prepared as described in 'Stability of CNPs in cell culture media', was incubated with A549 cells, NCI-H1650 or BEAS-2B for 24 and $48 \mathrm{~h}$; cytotoxicity was measured as the leakage of LDH into the extracellular medium, as an index of membrane damage and cell necrosis, using a Synergy HT microplate reader (Bio-Tek Instruments, VT, USA) as described [25]. Aerosil OX50 (nanosilica) (Degussa, Frankfurt, Germany) was used as positive control for cell death.

\section{Cellular uptake}

Cellular uptake of CNPs was qualitatively evaluated by TEM. A549 cells were incubated for $24 \mathrm{~h}$ with 80 or $160 \mu \mathrm{g} / \mathrm{ml}$ of CNPs. At the end of the exposure, cells were washed, detached and resuspended in $2 \%$ Karnovsky solution. Samples were then treated for TEM analysis, as detailed elsewhere [18].

\section{CNP phototoxicity in lung cell lines}

Cells were plated in 24-well plates at $5 \times 10^{4}$ cells/well in $0.5 \mathrm{ml}$ of Ham's F12; after $24 \mathrm{~h}$ the medium was replaced with $0.5 \mathrm{ml}$ phenol red-free RPMI supplemented with 10\% FBS, with CNPs at a final concentration of 80 or $160 \mu \mathrm{g} / \mathrm{ml}$, chosen on the basis of the LDH release in nonirradiated cells (see 'Results' section). After $24 \mathrm{~h}$ the cells were exposed for $15 \mathrm{~min}$ to NIR laser irradiation using a laser diode emitting a wavelength of $945 \mathrm{~nm}$ as a light source, at 3 or $1.5 \mathrm{~W} / \mathrm{cm}^{2}$. The laser light was conveyed through an optical fiber toward a lens adjusted in order to control the light spot dimension [26]. The temperature was monitored by means of a glass optic fiber sensor, a fiber Bragg grating, inscribed in a different fiber. After NIR irradiation, cells were maintained in culture for $24 \mathrm{~h}$. Afterward, the cell medium was discarded, and the cells were washed twice with phosphate-buffered saline (PBS), then each well was incubated with $500 \mu \mathrm{l}$ of crystal violet-methanol solution for $20 \mathrm{~min}$. Finally, the plates were washed with water and were left to dry before image acquisition using a Leica DC100 microscope (Leica Microsystems GmbH, Wetzlar, Germany).

\section{ROS measurement}

Cells were resuspended in $0.5 \mathrm{ml}$ PBS and incubated with $10 \mu \mathrm{mol} / 1$ of the ROS-sensitive probe 5-(and-6)chloromethyl-2', $7^{\prime}$-dichorodihydrofluorescein diacetate-acetoxymethyl ester (DCFDA) for $10 \mathrm{~min}$ at $37^{\circ} \mathrm{C}$. A 50- $\mu \mathrm{l}$ aliquot was used to measure cell proteins, and the remaining suspension was washed five times with PBS. The intracellular fluorescence of DCFDA was detected with a Synergy HT microplate reader (Bio-Tek Instruments), with $\lambda$ excitation $=504 \mathrm{~nm}$ and $\lambda$ emission $=530 \mathrm{~nm}$. The fluorescence value was normalized for the protein content and expressed as nmol DCFDA/mg cell proteins.

\section{Immunoblotting}

Cells were rinsed with ice-cold lysis RIPA buffer $\left(150 \mathrm{mM} \mathrm{NaCl}, 1.0 \%\right.$ Triton $^{T M} \mathrm{X}-100,0.5 \%$ sodium deoxycholate, $0.1 \%$ SDS and $50 \mathrm{mM}$ Tris, $\mathrm{pH} 8.0)$, supplemented with the protease inhibitor cocktail set III $(80 \mu \mathrm{M}$ aprotinin, $5 \mathrm{mM}$ bestatin, $1.5 \mathrm{mM}$ leupeptin, $1 \mathrm{mM}$ pepstatin; Calbiochem, CA, USA) and phenylmethylsulfonyl fluoride. The cells were then sonicated (Bandelin Sonopuls HD 3100) and centrifuged at 13,000 $\times g$ for 10 min at $4^{\circ} \mathrm{C}$. Then $10 \mu \mathrm{g}$ protein extracts were subjected to $4-20 \%$ gradient SDS-PAGE and probed with the following antibodies: anti-HSP70 (diluted 1:500; Abcam, Cambridge, UK), anti-HSP90 (diluted 1:500; Abcam), anti-caspase 3 (diluted 1:500; Abcam), anti-4-hydroxy-nonenal (HNE) (diluted 1:1000; Abcam), recognizing HNE-protein adducts, and anti-tubulin (diluted 1:500; Santa Cruz Biotechnology, Inc., CA, USA), as equal control loading. The membranes were incubated with peroxidase-conjugated secondary antibody (1:3000; Bio-Rad Laboratories, CA, USA) and washed with PBS-Tween $0.1 \% \mathrm{v} / \mathrm{v}$ solutions. Protein bands were detected by enhanced chemiluminescence (Bio-Rad). The quantification of band density was performed using the ImageJ software (https://imagej.nih.gov/ij/). The band density of control cells, expressed in arbitrary units, was considered 1; results were expressed as percentage versus control. The band densities were normalized on tubulin band density.

\section{DNA damage}

A549 cells $\left(2 \times 10^{4}\right)$ were seeded overnight onto glass coverslips in 24-well plates. Cells were then exposed to CNPs as described above. Sample were washed thrice with PBS and fixed using $4 \% \mathrm{w} / \mathrm{v}$ paraformaldehyde for $15 \mathrm{~min}$ at room temperature, washed with PBS, incubated for $10 \mathrm{~min}$ with PBS-Triton X-100-0.1\% v/v and then 
washed thrice with PBS. Samples were stored at $4{ }^{\circ} \mathrm{C}$ until incubation overnight at $4^{\circ} \mathrm{C}$ with anti-gamma $\mathrm{H} 2 \mathrm{AX}$ antibody (Abcam; diluted 1:100 in 1\% FBS/PBS). PBS was used to wash the samples five times; samples were then incubated for $1 \mathrm{~h}$ at room temperature with an Alexa Fluor ${ }^{\circledR}$ 488-conjugated secondary antibody (diluted 1:100 in 1\% FBS/PBS; Abcam). Then the cells were incubated with DAPI, diluted 1:10000 in PBS for 5 min and washed thrice with PBS. The samples were examined with a Leica DC100 fluorescence microscope. All samples were analyzed in duplicate, with at least 50 cells scored per sample. Quantification of the number of foci in each field was performed using the ImageJ software.

\section{Evaluation of in vitro degradation}

The CNPs were incubated in aqueous solutions containing human myeloperoxidase (hMPO) (Planta Natural Products, Vienna, Austria), coincubated or not with $\mathrm{H}_{2} \mathrm{O}_{2}$ and $\mathrm{NaCl}$, in order to investigate the propensity to degradation over time, using the same experimental design as previously reported for other CNMs [27]. Samples with a volume of $2 \mathrm{ml}$, containing $20 \mu \mathrm{g}$ of hMPO and $80 \mu \mathrm{g}$ of CNPs suspended in an aqueous solution of $\mathrm{NaCl}$ (final concentration $140 \mathrm{mM}$ ), were incubated at $37^{\circ} \mathrm{C}$ for 4 days; $8 \mu \mathrm{l}$ of a $20 \mathrm{mM}$ solution of $\mathrm{H}_{2} \mathrm{O}_{2}$ was continuously added during incubation every $1 \mathrm{~h}$ (six-times a day). Additions of fresh hMPO solution were also performed every $6 \mathrm{~h}$ (twice a day). Control samples were prepared as follows: CNPs in $\mathrm{NaCl}$, CNPs in $\mathrm{NaCl}+\mathrm{H}_{2} \mathrm{O}_{2}$, CNPs in $\mathrm{H}_{2} \mathrm{O}+\mathrm{H}_{2} \mathrm{O}_{2}+$ hMPO. UV-Vis spectrometry and Raman spectroscopy were used for monitoring the degradation of the samples. To evaluate the degradation in the presence of $\mathrm{NaClO}$, CNPs were suspended in PBS $(10 \mathrm{mM}, \mathrm{pH}$ 4.5) to obtain a final concentration of $40 \mu \mathrm{g} / \mathrm{ml}$, and $\mathrm{NaClO}$ was subsequently added to the suspension at a final concentration of $200 \mu \mathrm{M}$. The samples were incubated at $37^{\circ} \mathrm{C}$ for 4 days. $\mathrm{NaClO}$ was added daily and samples were analyzed at days 0, 2 and 4 using UV-Vis spectroscopy and Raman spectroscopy. Raman spectra of the CNP samples prepared as described above were recorded with a DXR ${ }^{T M}$ Raman confocal microscope (Thermo Scientific) equipped with a cell liquid accessory at days $0,2,4$ to evaluate the biodegradation. To this end, $2 \mathrm{ml}$ of each sample were placed in quartz cuvettes and the suspensions were analyzed using an excitation wavelength of $532 \mathrm{~nm}$ with a laser power of $10 \mathrm{~mW}$ and a spectrograph aperture of $50 \mu \mathrm{m}$ slit. Raman spectra were collected in the spectral range $3500-200 \mathrm{~cm}^{-1}$ with a resolution of $5 \mathrm{~cm}^{-1}$ using an exposure time of $1.5 \mathrm{~s}$ with $120 \mathrm{scans}$ in total. Raman spectra were normalized to the intensity of the $v_{\text {as }}(\mathrm{OH})$ of the water signal at around $3250 \mathrm{~cm}^{-1}$, baseline corrected and smoothed (Savitzky-Golay method, second polynomial order, 160 points of window) with Origin 8 Pro tools (MA, USA). Furthermore, UV-Vis spectra of aliquots of the same samples were recorded at days 0, 2 and 4: $2 \mathrm{ml}$ of each sample was placed in quartz cuvettes, $10-\mathrm{mm}$ path length, and the spectra were registered using Evolution $60 \mathrm{~s}$, Thermo Scientific, wavelength range 190-900 nm.

\section{Isolation of primary human immune cells}

Peripheral blood mononuclear cells (PBMCs) were isolated from buffy coats obtained from healthy human blood donors (Karolinska University Hospital, Stockholm, Sweden) by density gradient centrifugation using Lymphoprep $^{T M}$, as described previously [28]. Then the PBMCs were positively selected for CD14 expression using CD14 MicroBeads (Miltenyi Biotech Ltd, Bergisch Gladbach, Germany). To obtain human monocyte-derived macrophages (HMDMs), CD14 ${ }^{+}$monocytes were cultured in RPMI-1640 cell medium supplemented with $2 \mathrm{mM}$ L-glutamine, $100 \mathrm{IU} / \mathrm{ml}$ penicillin, $100 \mu \mathrm{g} / \mathrm{ml}$ streptomycin and $10 \%$ heat-inactivated FBS, supplemented with $50 \mathrm{ng} / \mathrm{ml}$ recombinant macrophage colony-stimulating factor (M-CSF) (R\&D Systems, MN, USA) for 3 days. Peripheral blood neutrophils (PMNs) were isolated from buffy coats as previously described [29]. Briefly, neutrophils were isolated by density gradient centrifugation using Lymphoprep ${ }^{T M}$ followed by gradient sedimentation in a $5 \%$ dextran solution and hypotonic lysis of residual erythrocytes. Neutrophils from at least three independent donors were used immediately upon isolation for cytotoxicity and degradation experiments (see below).

\section{Cytotoxicity assessment in primary cells}

alamarBlue assay

Freshly isolated HMDMs and PMNs were seeded in 96-well plates in phenol red-free RPMI-1640 cell medium at a density of $10^{6}$ cells $/ \mathrm{ml}$ and exposed to CNPs at the indicated concentrations or were maintained in cell medium alone (negative control). The alamarBlue ${ }^{T M}$ assay (Thermo Scientific, Göteborg, Sweden) was performed for cytotoxicity assessment of the PMNs and HMDMs as described previously [29]. Briefly, following exposure to CNPs, a $10 \%(\mathrm{v} / \mathrm{v})$ solution of alamarBlue reagent was added to each well. After $3 \mathrm{~h}$ of incubation at $37^{\circ} \mathrm{C}$, fluorescence was measured at excitation and emission wavelengths of 531 and $595 \mathrm{~nm}$ using a Tecan Infinite 
F200 plate reader (Männedorf, Switzerland). The experiment was performed with at least three donors and three technical replicates for each concentration of CNPs.

\section{$L D H$ release}

The LDH release assay was performed to further evaluate cytotoxicity toward HMDMs using the CytoTox96 ${ }^{\circledR}$ nonradioactive cytotoxicity kit (Promega G1780, Madison, USA) as described [28]. The samples were analyzed using a Tecan Infinite F200 plate reader. The percentage of cell viability was calculated based on the ratio between the absorbance of each sample compared with the negative control. Experiments were performed with at least three independent human donors and three technical replicates.

\section{Neutrophil degranulation \& degradation}

Neutrophils were assessed for degranulation by flow cytometric analysis, as described before [29]. Briefly, externalized MPO was detected by fluorescein isothiocyanate (FITC)-labeled antibody according to the manufacturer's instructions for the FITC anti-human flow kit (Biolegend, CA, USA). To this end, freshly isolated primary human neutrophils were seeded in phenol red-free RPMI-1640 cell medium (Sigma-Aldrich, Darmstadt, Germany) at a density of $10^{6}$ cells $/ \mathrm{ml}$ and exposed to CNPs at a noncytotoxic dose $(20 \mu \mathrm{g} / \mathrm{ml})$. As a positive control for degranulation, neutrophils were incubated with N-formil-metionil-leucil-fenilalanina (fMLP, $10 \mathrm{nM}$ ) and cytochalasin B $(5 \mu \mathrm{g} / \mathrm{ml})$ (Sigma-Aldrich). The samples were incubated with $20 \mu \mathrm{l}$ FITC-conjugated MPO antibody for $30 \mathrm{~min}$ and analyzed on the BD LSRFortess ${ }^{T M}$ cell analyzer (BD Bioscience, CA, USA). To study degradation, freshly isolated neutrophils $\left(10^{6} \mathrm{cells} / \mathrm{ml}\right)$ were seeded in phenol red-free RPMI-1640 medium supplemented with $10 \%$ FBS and incubated with CNPs at $20 \mu \mathrm{g} / \mathrm{ml}$. Samples were collected at $6 \mathrm{~h}$ and washed with PBS and centrifuged to pellet the samples; pellets were resuspended in PBS and stored at $-80^{\circ} \mathrm{C}$ for further analysis. To detect biodegradation of CNPs, $5 \mu$ l of pellet suspension were drop casted on a silicon wafer and air-dried. Raman analysis was then carried out using a DXR ${ }^{T M}$ Raman confocal microscope (Thermo Scientific) equipped with an excitation laser source at $532 \mathrm{~nm}$, a laser power of $2 \mathrm{~mW}$, a $20 \times$ long working distance microscope objective and a $50-\mu \mathrm{m}$ pinhole spectrograph aperture. Several line maps were recorded on different positions of the drop-casted area to provide significant statistical results. Each spectrum of the map was registered in the spectral range $3500-200 \mathrm{~cm}^{-1}$ with a resolution of $5 \mathrm{~cm}^{-1}$ using an exposure time of $1 \mathrm{~s}$ with 70 scans in total.

\section{Endotoxin content}

CNP samples were assessed for endotoxin content with the TNF- $\alpha$ expression test, which enables unequivocal detection of endotoxin with a sensitivity comparable to that of the conventional limulus amebocyte lysate (LAL) assay but without any interference with the assay [30]. In brief, PBMCs were isolated from buffy coats obtained from healthy human blood donors by density gradient centrifugation. Then PBMCs were positively selected for CD14 expression with CD14 MicroBeads. HMDMs were obtained as described in the section 'Isolation of primary human immune cells' and maintained in medium supplemented with $50 \mathrm{ng} / \mathrm{ml}$ recombinant M-CSF for 3 days in 96-well plates. HMDMs were exposed to CNP $(40 \mu \mathrm{g} / \mathrm{ml})$ or to bacterial lipopolysaccharides (LPS; Sigma-Aldrich) in the presence or absence of the specific LPS inhibitor polymyxin B (10mM) (Sigma-Aldrich), and TNF- $\alpha$ secretion was measured at $24 \mathrm{~h}$ of exposure with a human TNF- $\alpha$ ELISA kit (Mabtech, Nacka Strand, Sweden).

\section{Flow cytometry}

Expression of the surface markers CD86 and CD206 on HMDM exposed to CNP $(20 \mu \mathrm{g} / \mathrm{ml})$ was assessed by flow cytometry using the following antibodies: FITC-conjugated CD86 and CD206 antibody (BD Pharmingen, CA, USA). Briefly, $3 \times 10^{5} \mathrm{HMDM}$ (differentiated with M-CSF) were resuspended in $100 \mu \mathrm{l}$ of PBS and incubated with the specific antibody or isotype control antibody for $1 \mathrm{~h}$ in the dark. Cells were then washed three times with cold PBS and resuspended in PBS. The samples were analyzed with the BD LSRFortessa ${ }^{\mathrm{TM}}$ cell analyzer operating with FCS Express 7 software.

\section{Cytokine detection}

Cell culture supernatants from HMDM exposed to CNP $(20 \mu \mathrm{g} / \mathrm{ml})$ were harvested and kept at $80^{\circ} \mathrm{C}$ until further analysis. TNF- $\alpha$ (Mabtech) and IL-10 (Thermo Fisher, Vienna, Austria) expression in supernatants was determined by ELISA according to the manufacturer's instruction. Absorbance was measured at $450 \mathrm{~nm}$ using a Tecan Infinite 


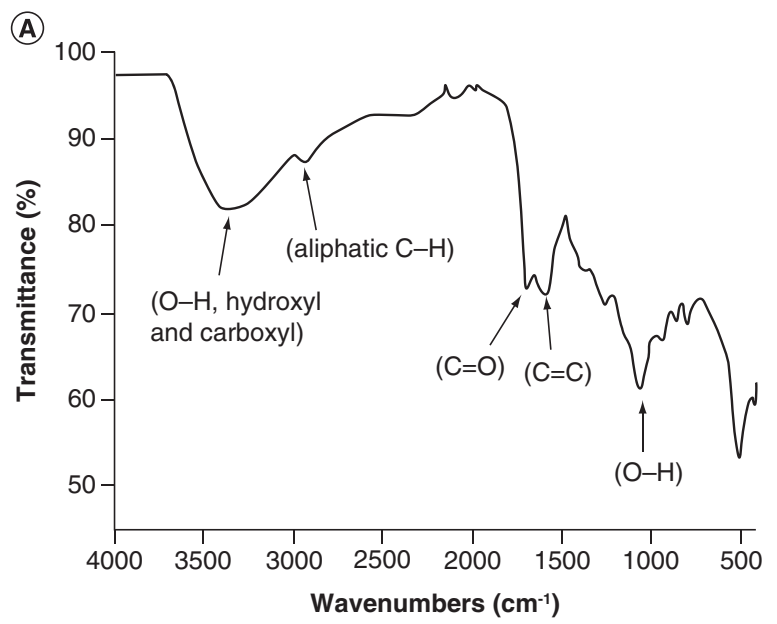

(B)

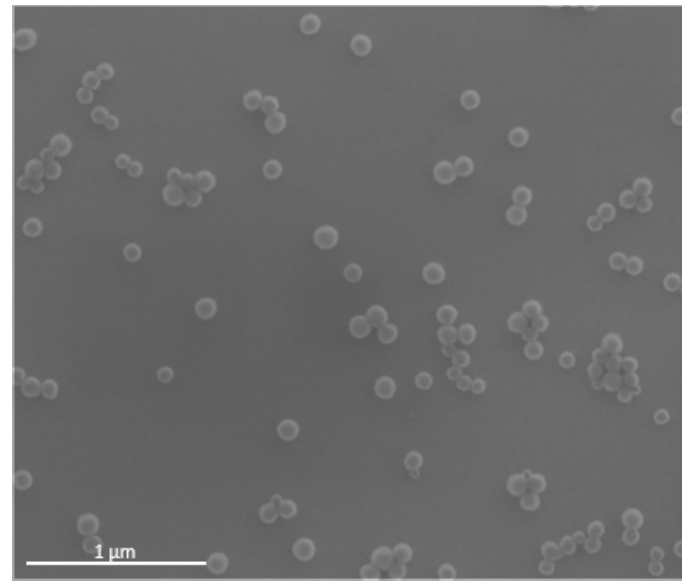

Figure 1. Characterization of carbon nanoparticles. (A) Attenuated total reflection-Fourier transformed infrared spectrum of carbon nanoparticles. (B) Representative scanning electron micrograph of carbon nanoparticles at $80,000 \times$ magnification.

F200 plate reader. Results are expressed as $\mathrm{pg} / \mathrm{ml}$ of released cytokine, based on three independent experiments using cells from different donors.

\section{Statistical analysis}

All data shown are mean values \pm standard error of the mean. Statistical analysis was performed by one-way analysis of variance using GraphPad Prism 8.0 (GraphPad, CA, USA); p < 0.05 was considered significant.

\section{Results}

\section{Synthesis, characterization \& sterilization of CNPs}

CNPs were synthesized by hydrothermal carbonization route, as previously described [18]. In this study, we also demonstrate that CNPs are mainly composed of amorphous carbon; however, graphitic domains are embedded inside the amorphous matrix as previously demonstrated [18]. The hydrodynamic diameter and the $\zeta$-potential of the CNPs produced here are comparable to those obtained previously $\left(\mathrm{d}_{\mathrm{H}}=163.7 \pm 3.522\right.$; polydispersity index $=0.098 \pm 0.020 ; \zeta$-potential $=-46.4 \pm 1.30 \mathrm{mV}$ ) [18], suggesting the presence of acidic sites at the surface that deprotonates in water, generating a dense negative charge. To identify these acidic species, FTIR analysis was performed (Figure 1A). The data evidenced a strong and large band at 3500-3250 $\mathrm{cm}^{-1}$ corresponding to hydroxyl or carboxyl $\mathrm{O}-\mathrm{H}$ stretching vibration [31], and a strong band at $1700 \mathrm{~cm}^{-1}$ which is related to the stretching vibration of $\mathrm{C}=\mathrm{O}$ bonds in carbonyl or carboxyl groups [32]. A representative SEM image depicting the uniform size and morphology of the CNPs is shown in Figure 1B. High-resolution TEM analysis (Supplementary Figure 1) confirmed the spherical shape of the particles and the presence of crystalline domains of turbostratic graphite [18]. Sterilization of NPs is required to avoid bacterial contamination that can interfere with the outcome of in vitro tests. However, the thermal treatment might modify the properties of the material by inducing agglomeration, modification of the bulk structure or decarboxylation. For this reason, sterilized CNPs were characterized in order to reveal possible modifications of their properties. After sterilization, the CNPs were negatively charged, with a $\zeta$-potential similar to the pristine one $(-47.4 \pm 1.33 \mathrm{mV})$ and monodispersed with a distribution of $\mathrm{d}_{\mathrm{H}}$ that almost overlapped with those of the pristine CNPs (Supplementary Figure 2A). Thermogravimetric analysis was performed to reveal possible graphitization of the CNPs (Supplementary Figure 2B). A major weight loss in the temperature range of $200-600^{\circ} \mathrm{C}$ was observed, corresponding to decarboxylation and restructuring of the CNPs. The curves are perfectly superimposable, indicating that the CNPs subjected to sterilization have not undergone changes to their surface or internal structure. Finally, the agar plate test confirmed that the autoclaved CNPs were uncontaminated (Supplementary Figure 2C). Moreover, the CNPs were evaluated using a human macrophage-based assay, as discussed below, and shown to be endotoxin-free (see 'Macrophage polarization and cytokine responses', below). 
Stability of CNPs in cell culture media

Evaluation of the stability of CNPs in cell culture media was performed by dynamic light scattering in order to monitor possible agglomeration during incubation. The nanoparticles exhibited good stability over time in RPMI-1640 cell culture medium (used for primary human immune cells) (Supplementary Figure 3A) as the mean hydrodynamic diameter did not change significantly up to $24 \mathrm{~h}$. To monitor possible adsorption of serum proteins, the $\zeta$-potential was evaluated by electrophoretic light scattering. The results showed a shift of $\zeta$-potential in medium supplemented with 10\% FBS toward less negative values, suggesting that proteins adsorb to the surface of the CNPs (Supplementary Figure 3B). Nevertheless, the reduction of electrostatic repulsion among particles did not induce agglomeration, suggesting a stabilizing effect of proteins by a steric repulsion. High stability was also evidenced in Ham's F12 supplemented with 10\% FBS (used for the A549 lung cancer cells) up to $48 \mathrm{~h}$ (Supplementary Figure 3C).

Cytotoxicity assessment of CNPs using lung cancer cells \& human bronchial epithelial cells

CNPs were firstly tested for their impact on two different human lung adenocarcinoma cell lines (A549 and NCI-H1650) and on human bronchial epithelial cells (BEAS-2B) in the absence of NIR activation by evaluating the leakage of LDH into the extracellular medium. Cells were incubated for $24 \mathrm{~h}$ with CNPs at $10-160 \mu \mathrm{g} / \mathrm{ml}$. Pyrogenic silica was used as positive control [33]. The results showed that CNPs did not elicit any cytotoxic effects, even when administered at high doses $(160 \mu \mathrm{g} / \mathrm{ml})$ in the absence of activation (Supplementary Figure 4)

\section{Cytotoxicity of NIR-activated CNPs toward lung cancer cells}

We previously demonstrated that CNPs are able to produce singlet oxygen and heat when irradiated with NIR [18]. Here we investigated whether these properties can be exploited to kill tumor cells. To establish the optimal CNP concentration, we first tested CNPs at the two highest concentrations $(160$ and $80 \mu \mathrm{g} / \mathrm{ml}$ ) of those tested in nonirradiated A549 cells, chosen as a prototypical lung adenocarcinoma cell line. These concentrations were unable to significantly damage the plasma membrane, as demonstrated by the lack of LDH increase. CNPs were activated using a laser diode emitting at a wavelength of $945 \mathrm{~nm}$, at a power density of $3 \mathrm{~W} / \mathrm{cm}^{2}$ (Figure $2 \&$ Supplementary Figure 5). The effect of CNPs was compared with that of the NIR radiation only, to exclude a direct toxic effect of the irradiation. Cell viability was monitored by crystal violet staining and optical microscopy.

The exposure to the laser beam with a potency of $3 \mathrm{~W} / \mathrm{cm}^{2}$ (Figure $2 \mathrm{~A}$ ) did not decrease the viability of cells in the absence of CNPs up to $15 \mathrm{~min}$ of irradiation. We therefore chose this timing fixed as a nontoxic irradiation condition that allowed us to evaluate the phototoxicity due to NIR activation of the particles. Under irradiation, a dramatic decrease of A549 cell viability was observed at both 80 and $160 \mu \mathrm{g} / \mathrm{ml}$ (Figure $2 \&$ Supplementary Figure 5), coupled with a strong increase $\left(>50^{\circ} \mathrm{C}\right)$ of temperature (Figure $2 \mathrm{~B} \&$ Supplementary Figure 5B). Notably, the temperature also increased in cells without CNPs following NIR irradiation; however, the temperature in the presence of CNPs was significantly higher than that recorded in cells exposed to the laser beam only, confirming the photothermal activity of CNPs.

\section{Cellular uptake of CNPs in lung cancer cells}

TEM analysis was performed on A549 cells to monitor the uptake of CNPs at concentrations of 80 and $160 \mu \mathrm{g} / \mathrm{ml}$. Representative images of cells exposed to CNPs for $24 \mathrm{~h}$ are shown in Figure 3. Unexposed A549 cells are shown in Figure 3A for comparison. The TEM images showed a similar internalization of the nanoparticles at both concentrations. The amount of internalized particles at $80 \mu \mathrm{g} / \mathrm{ml}$ was quantified and a mean number of particles/cell of $30.9 \pm 7.2$ was found. Indeed, numerous clusters of CNPs were present in cellular organelles (endosomes). No particles were found in the cell nucleus, and no abnormal ultrastructural features were present in cells exposed to CNPs.

Because the two tested doses elicited similar cytotoxic effects (Figure $2 \&$ Supplementary Figure 5) and uptake (Figure 3), the lowest $(80 \mu \mathrm{g} / \mathrm{ml})$ was chosen to evaluated the intracellular events that may explain the photothermal activity of CNPs.

\section{Heat shock \& DNA damage response}

To further confirm that the cytotoxic effect observed was due to the photothermal activity of CNPs, the expression of heat shock proteins (HSPs) was evaluated. HSPs are molecular chaperones that preserve the integrity of cellular proteins subjected to various forms of stress, including sudden temperature increases [34]. Immunoblot analysis was 
(A)

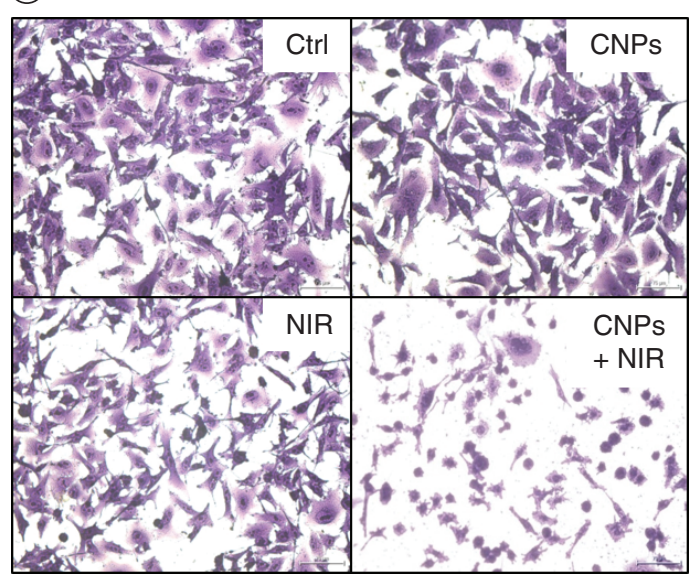

(B)

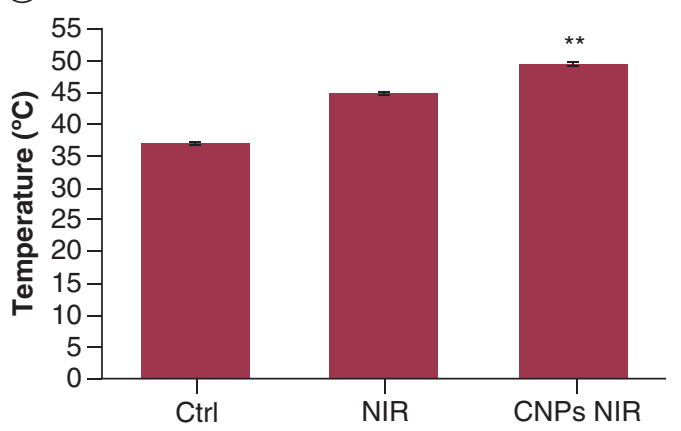

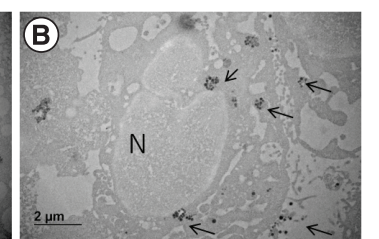

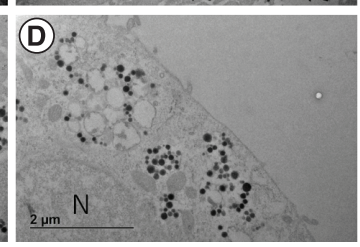

Figure 2. Effect of near infrared-activated carbon nanoparticles on A549 cells. (A) Cells not irradiated (ctrl) or irradiated with a NIR laser (NIR), irradiance $3 \mathrm{~W} / \mathrm{cm}^{2}$, for $15 \mathrm{~min}$; cells exposed to CNPs $(80 \mu \mathrm{g} / \mathrm{ml})$ (CNPs) or cells exposed to CNPs $(80 \mu \mathrm{g} / \mathrm{ml})$ and irradiated by NIR laser (CNPs $+\mathrm{NIR}$ ), irradiance $3 \mathrm{~W} / \mathrm{cm}^{2}$, for $15 \mathrm{~min}$. Bars $=75 \mu \mathrm{m}$. (B) Temperature after NIR irradiation of A549 cells for $15 \mathrm{~min}$, at $3 \mathrm{~W} / \mathrm{cm}^{2}$ irradiance in the absence or in the presence of $80 \mu \mathrm{g} / \mathrm{ml} \mathrm{CNPs} \mathrm{compared} \mathrm{with} \mathrm{ctrl} \mathrm{(no} \mathrm{irradiation} \mathrm{and} \mathrm{CNPs).}$ $* * \mathrm{p}<0.01$.

CNP: Carbon nanoparticle; Ctrl: Control; NIR: Near infrared.
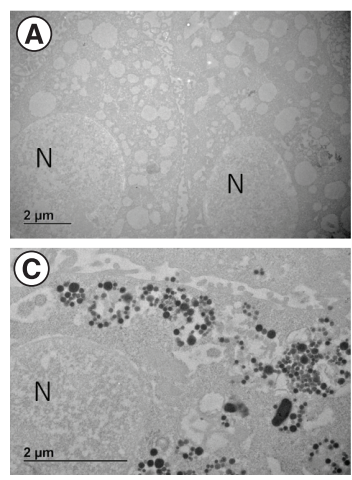

Figure 3. Uptake of nonactivated carbon nanoparticles toward A549 cells. Representative transmission electron microscopy images of cells. (A) Unexposed cells. (B \& C) Cells exposed to carbon nanoparticles (CNPs) $(80 \mu \mathrm{g} / \mathrm{ml}, 24 \mathrm{~h}) ;(D)$ Cells exposed to CNPs $(160 \mu \mathrm{g} / \mathrm{ml}, 24 \mathrm{~h})$. The arrows indicate internalized CNPs.

CNP: Carbon nanoparticle; N: Nucleus.

performed to evaluate the expression of HSP70 and HSP90 (Figure 4A \& B). An increase of both HSP70 and HSP90 expression was observed in cells treated with CNPs or subjected to NIR treatment, although the values were significant only for HSP70 in cells treated with NIR-activated CNPs. These results correlated well with the observed temperature increase following NIR + CNPs coexposure.

To further assess the in vitro therapeutic efficacy of CNPs as phototoxic agents toward lung cancer cells, the amount of phospho- $\gamma-\mathrm{H} 2 \mathrm{AX}$, a well-known marker of DNA damage, was measured after exposure of A549 cells to CNPs following NIR irradiation. The phosphorylation on Ser139 of $\gamma$-H2AX histone is a sensitive marker of DNA lesions, as it occurs on the sites of double-strand breaks [35]. Confocal images obtained on cells are shown in Figure 4C, where cell nuclei are marked in blue and $\gamma-\mathrm{H} 2 \mathrm{AX}$ foci correspond to green spots. The foci number quantification is displayed in Figure 4D. These results evidenced that in the absence of laser irradiation, untreated cells or cells exposed to CNPs exhibited no DNA damage, confirming the lack of toxicity of CNPs themselves. In contrast, few $\gamma$-H2AX foci were observed in the NIR-treated group. However, when cells were exposed to both CNPs and NIR, the phosphorylation level was dramatically higher than in irradiated cells not exposed to CNPs. 


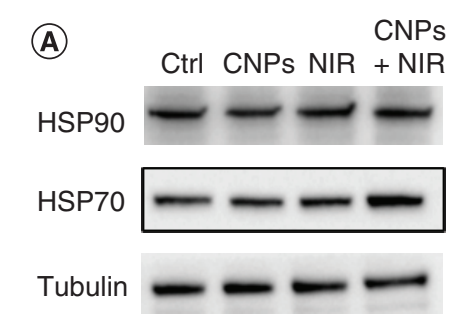

(B)

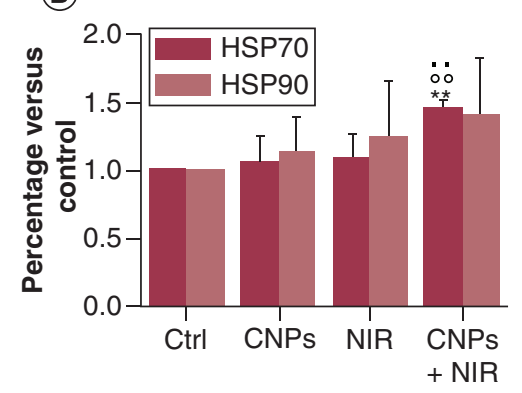

(D)

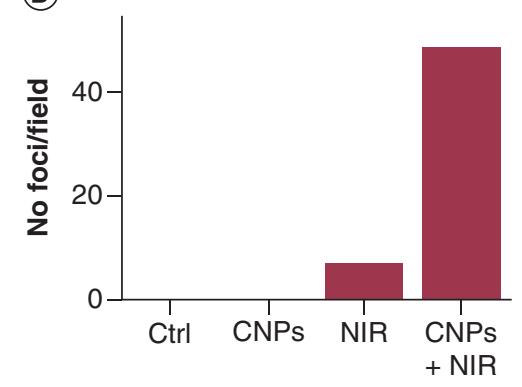

(C)
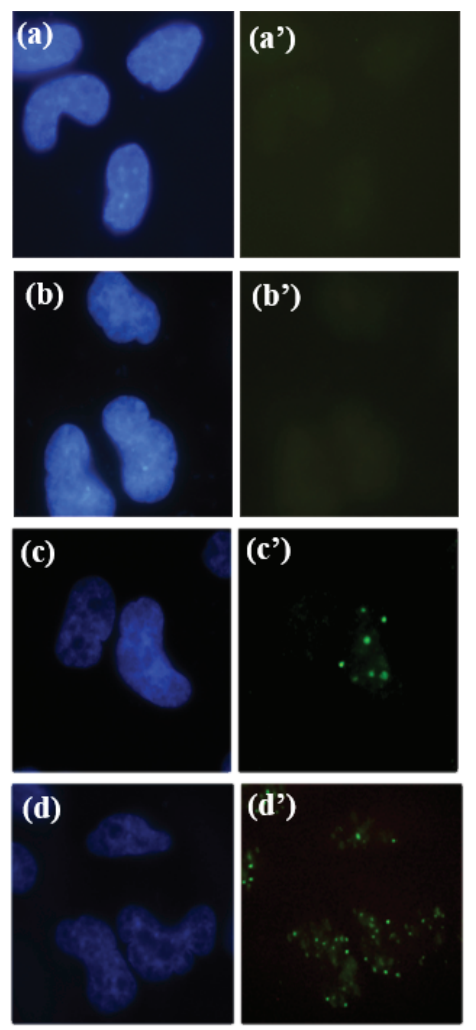

Figure 4. Heat shock and DNA damage response. (A) Western blot analysis of heat shock proteins after treatment with nonactivated or NIR-activated CNPs $\left(80 \mu \mathrm{g} / \mathrm{ml}, 3 \mathrm{w} / \mathrm{m}^{2}\right.$ irradiance, $\left.15 \mathrm{~min}\right)$. (B) Quantification of HSP70 and HSP90 (\% vs ctrl, tubulin loading control). ${ }^{* *} \mathrm{p}<0.01$ versus ctrl; ${ }^{\circ} \mathrm{p}<0.01$ versus CNPs; $\mathrm{p}<0.01$ versus ctrl $+\mathrm{NIR}$. (C) Representative fluorescence microscopy images from $\gamma$-H2AX immunofluorescent staining performed $24 \mathrm{~h}$ post-treatment. (a-a'): A549 cells nonirradiated (ctrl-); (b-b'): A549 cells exposed to CNPs (80 $\mu \mathrm{g} / \mathrm{ml}, 24$ h); (c-c'): A549 irradiated with NIR laser; (d-d'): A549 cells exposed to CNPs and irradiated with NIR laser. Green: $\gamma$-H2AX; blue: nuclei. (D) Quantification of the number of foci number/field, performed with the ImageJ software.

CNP: Carbon nanoparticle; ctrl: Control; NIR: Near infrared.

Given that DNA damage may be correlated with oxidative stress, we performed experiments with $1.5 \mathrm{~W} / \mathrm{cm}^{2}$ irradiation for $15 \mathrm{~min}$; that is, a laser power that did not increase the temperature to cytotoxic values nor induce a photothermal-mediated cell death (Supplementary Figure 6). We also increased the CNP concentration to $160 \mu \mathrm{g} / \mathrm{ml}$ in order to maximize the amount of singlet oxygen released [18]. Under these conditions, ROS were not significantly increased in CNP-treated, irradiated cells (Supplementary Figure 7A). Note that ROS release was also not detected at higher laser power $\left(3 \mathrm{~W} / \mathrm{cm}^{2}\right.$, data not shown). To exclude a possible technical bias, we also measured HNE-protein adducts, as stable markers of oxidative damage, by immunoblotting (Supplementary Figure $7 \mathrm{~B} \& \mathrm{C}$ ). There was no induction of HNE in any experimental conditions, except for a small increase in cells irradiated and exposed to CNPs, indicating the occurrence of slight but not significant oxidative damage.

\section{Enzymatic degradation of CNPs in a cell-free system}

We and others have previously shown that $\mathrm{CNMs}$ are susceptible to biodegradation [16], but whether this applies to CNPs is not known. To gain insight into the possible biodegradability of CNPs, we performed in vitro (i.e., cell-free) experiments in which CNPs were incubated with hMPO, $\mathrm{NaClO}$ and/or $\mathrm{H}_{2} \mathrm{O}_{2}$. Degradation was evaluated by UV-Vis and Raman spectroscopies. As shown in Figure 5A, a dramatic decrease of UV-Vis adsorption and an obvious change of color in the suspension were observed for CNPs incubated for 4 days with hMPO, indicative of 


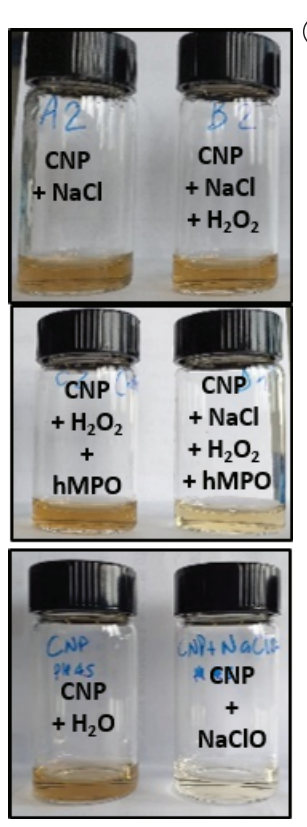

(E)

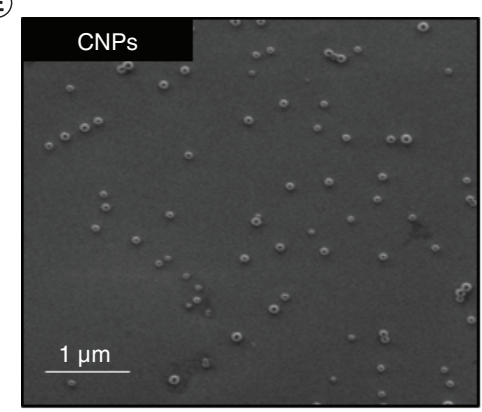

(A)

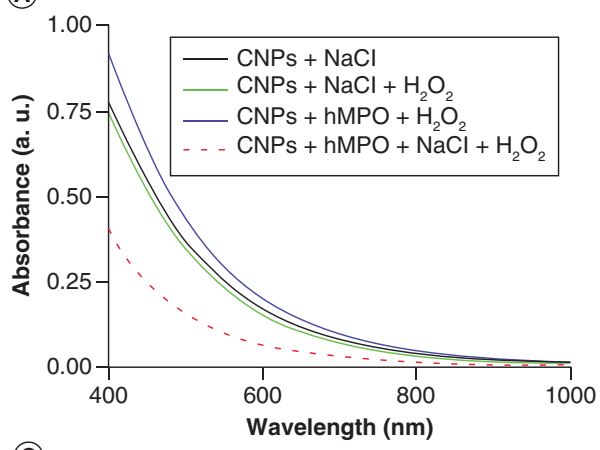

(C)

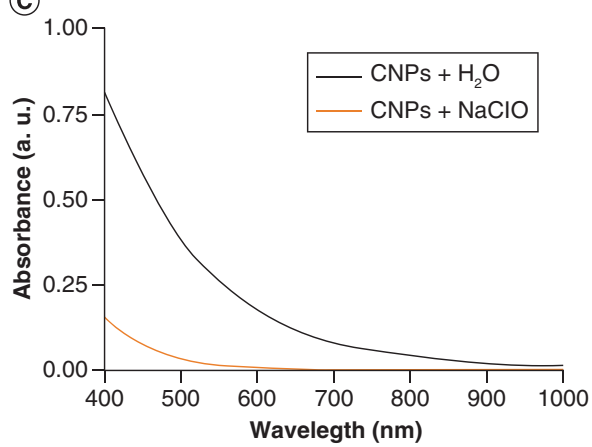

(B)

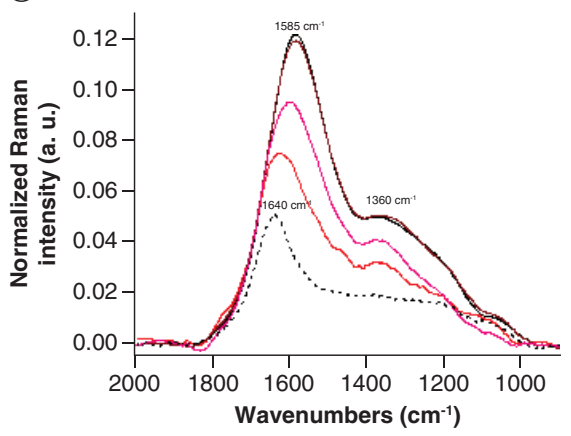

- CNPs $96 \mathrm{~h}$

$\mathrm{CNPS}+\mathrm{NaCl}$

$+\mathrm{hMPO}+\mathrm{H}_{2} \mathrm{O}_{2} \mathrm{Oh}$

- $\mathrm{CNPS}+\mathrm{NaCl}$

$+\mathrm{hMPO}+\mathrm{H}_{2} \mathrm{O}_{2} 24 \mathrm{~h}$

- $\mathrm{CNPS}+\mathrm{NaCl}$

$+\mathrm{hMPO}+\mathrm{H}_{2} \mathrm{O}_{2} 96 \mathrm{~h}$

..... $\mathrm{NaCl}$
(D)

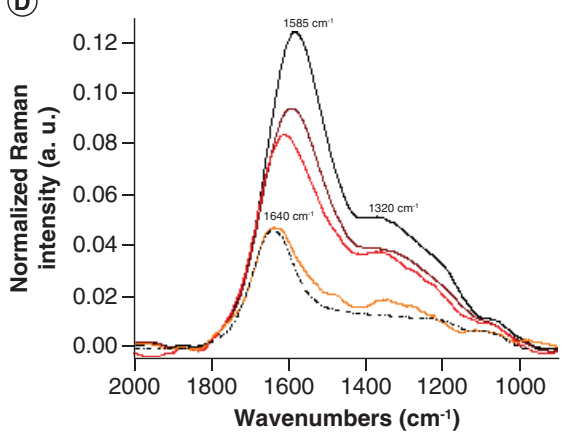

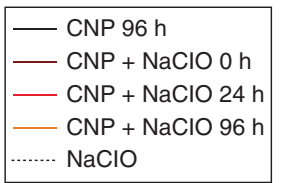

Figure 5. Cell-free degradation of carbon nanoparticles. (A \& B) UV-Vis spectra recorded after incubation of CNPs in (A) hMPO and (B) $\mathrm{NaClO}$ for 4 days; in the left panels is shown the color of the suspensions. (C \& D) Raman spectra recorded on CNP suspensions incubated with (C) hMPO and (D) NaClO, at days 0, 2 and 4. (E) Representative SEM micrographs of CNPs treated with NaClO for 4 days compared with the untreated ones.

CNP: Carbon nanoparticle; SEM: Scanning electron microscopy.

degradation. The simultaneous presence of $\mathrm{NaCl}$ and $\mathrm{H}_{2} \mathrm{O}_{2}$ was essential for the hMPO-mediated degradation of CNPs, suggesting a role of hypochlorite in the reaction.

To provide further evidence for this mechanism, CNPs were incubated with $\mathrm{NaClO}(200 \mu \mathrm{M})$ or $\mathrm{H}_{2} \mathrm{O}_{2}(200 \mu \mathrm{M})$. CNPs appeared resistant to oxidation by hydrogen peroxide (data not shown). However, the CNPs were rapidly degraded by $\mathrm{NaClO}$ (Figure 5B).

Raman spectroscopy was used to confirm the ability of hMPO to degrade CNPs. Spectra were registered at days 0 , 2 and 4 and are displayed in Figure 5C. The spectra of CNPs are characterized by two overlapping bands at around $1585 \mathrm{~cm}^{-1}$ (the $\mathrm{G}$ band), corresponding to graphitic lattice vibration mode, and at $1360 \mathrm{~cm}^{-1}$ (the D band), whose intensity is indicative of disorder in the graphitic structure [18]. We noted a marked, time-dependent decrease in the intensity of the characteristic D and G bands together with a shift of the G bands at higher wavenumbers due to the appearance of the $\delta\left(\mathrm{H}_{2} \mathrm{O}\right)$ vibration at $1640 \mathrm{~cm}^{-1}$. A similar effect was observed with hypochlorite (Figure 5D). After 4 days of incubation, only the band corresponding to $\delta\left(\mathrm{H}_{2} \mathrm{O}\right)$ vibration was visible. The complete degradation of CNPs by hypochlorite was also confirmed by SEM (Figure 5E). 
(A)

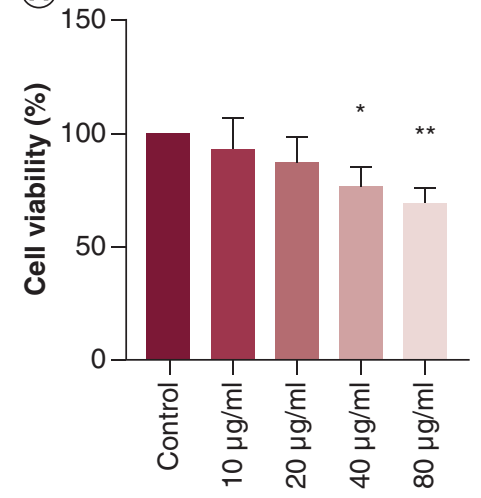

(C)

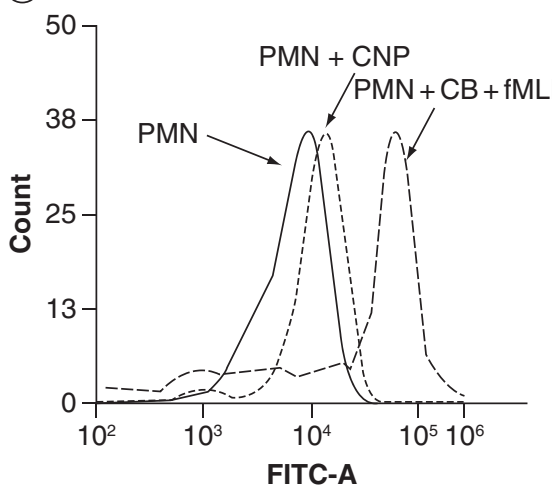

(B)

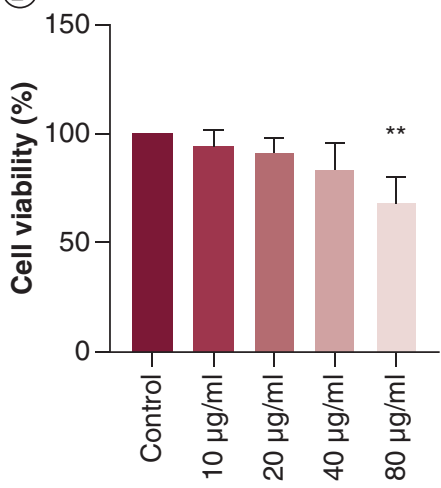

(D)

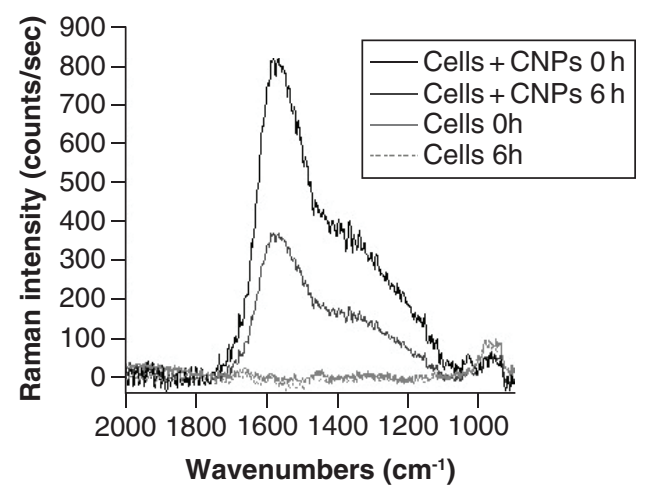

Figure 6. Degradation of carbon nanoparticles by neutrophils. (A \& B) Cell viability of freshly isolated PMNs exposed to CNPs up to $80 \mu \mathrm{g} / \mathrm{ml}$ by alamarBlue assay for (A) 3 and (B) $6 \mathrm{~h}$. (C) Flow cytometry analysis: fluorescence intensity of PMNs stained with FITC-labelled MPO antibody exposed to CNPs at $20 \mu \mathrm{g} / \mathrm{ml}$ for $3 \mathrm{~h}$. (D) Degradation of CNPs.

Representative Raman spectra recorded on treated and untreated cells at $t=0$ and $t=6 \mathrm{~h}$.

CB: Cytochalasin B; CNP: Carbon nanoparticle; FITC: Fluorescein isothiocyanate; fMLP: Fenilalanina; PMN: Peripheral blood neutrophil.

\section{Neutrophil degradation of CNPs}

Neutrophils play a key role in inflammation and host defense [36]. We therefore evaluated cell viability in freshly isolated PMNs exposed to CNPs for 3 and 6 h by using the alamarBlue assay (Figure 6A \& B). We observed a moderate, dose-dependent cytotoxicity. Next, we asked whether CNPs would trigger activation of neutrophils. To this end, we evaluated degranulation by monitoring the release of MPO by flow cytometry. The well-known agonists fMLP and cytochalasin B were used as a positive control for degranulation [27]. As shown in Figure 6C, exposure for $3 \mathrm{~h}$ to CNPs $(20 \mu \mathrm{g} / \mathrm{ml})$ caused degranulation, albeit less pronounced as compared with fMLP + cytochalasin B. Next, we asked whether neutrophils are capable of biodegradation of CNPs, as shown previously for other CNMs [27]. To this end, we cocultured PMNs with a noncytotoxic concentration of CNPs $(20 \mu \mathrm{g} / \mathrm{ml})$ and harvested the samples at $6 \mathrm{~h}$ for analysis by Raman spectroscopy. We noted a clear decrease in the intensity of both $\mathrm{D}$ and $\mathrm{G}$ bands (Figure 6D). These data suggest that CNPs can be degraded by PMNs, thus confirming the results obtained in acellular experiments.

\section{Macrophage polarization \& cytokine responses}

To evaluate the biocompatibility of CNPs, HMDMs were exposed to increasing amounts of CNPs for $24 \mathrm{~h}$ and cell viability was assessed by using the alamarBlue assay and LDH release assay (Figure 7A \& B). No cytotoxicity was observed even at the highest concentration $(80 \mu \mathrm{g} / \mathrm{ml})$. To further understand the impact of CNPs on macrophage activation status, we next decided to investigate pro- and anti-inflammatory cytokine release and cell surface markers known to be associated to proinflammatory (M1) or anti-inflammatory (M2) macrophages after $24 \mathrm{~h}$ exposure to CNPs. Classically activated M1 macrophages secrete TNF- $\alpha$, a proinflammatory cytokine, which was upregulated significantly after exposure to CNPs at $20 \mu \mathrm{g} / \mathrm{ml}$, as shown in Figure 7C, in line with the previous 
(A)

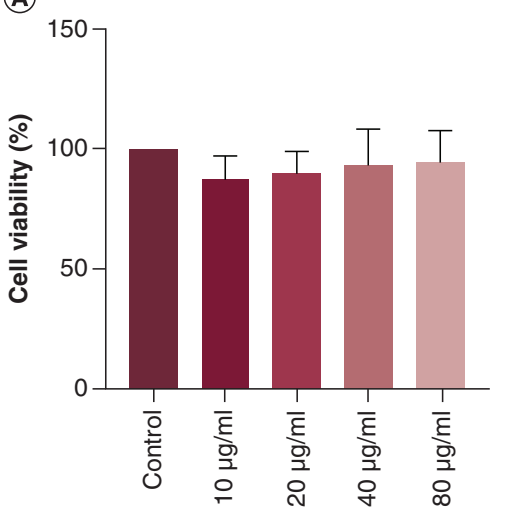

(C)

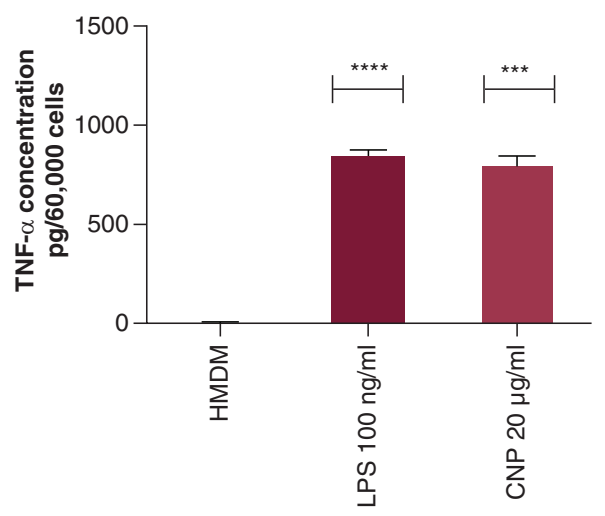

(E) - Isotype HMDM - - CD206 control

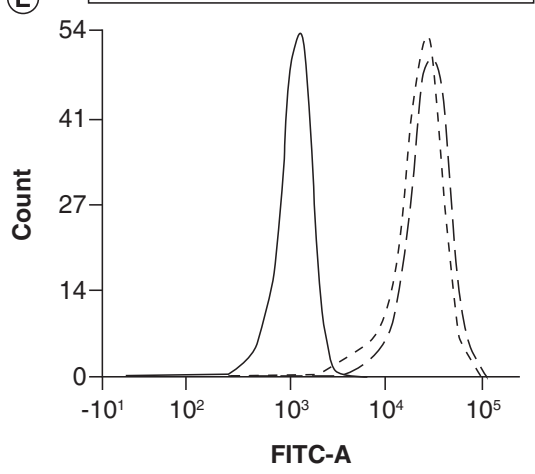

(B)

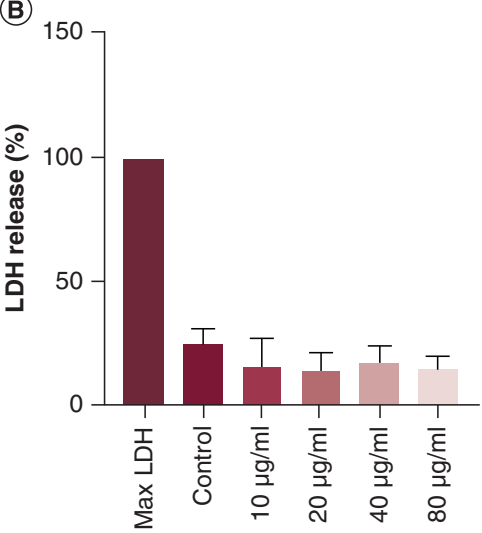

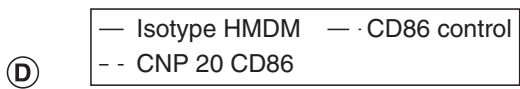

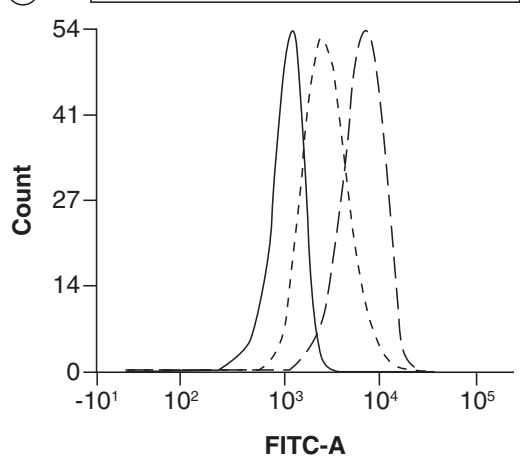

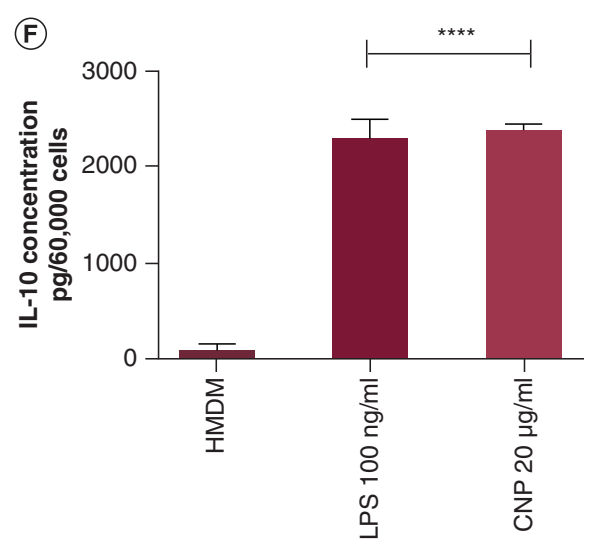

Figure 7. Effect of carbon nanoparticles on macrophage polarization and cytokine responses. (A \& B) Cell viability of human monocyte-derived macrophages in the presence of increasing amounts of CNPs for $24 \mathrm{~h}$ by (A) alamarBlue assay and (B) LDH release assay. (C \& F) Expression of (C) TNF- $\alpha$ and (F) IL-10. Data are mean values of three independent experiments \pm standard deviation $(n=2)$. ${ }^{*} p<0.05, * * p<0.01, * * p<0.001, * * * p<0.0001$, $* * * * p<$ 0.00001. (D \& E) Flow cytometry analysis of macrophage surface marker expression. Representative histogram showing fluorescence of (D) CD86 and (E) CD206 in the presence of CNPs $20 \mu \mathrm{g} / \mathrm{ml}$. The isotype-matched control antibody is represented as a black line.

CNP: Carbon nanoparticle; FITC: Fluorescein isothiocyanate. 


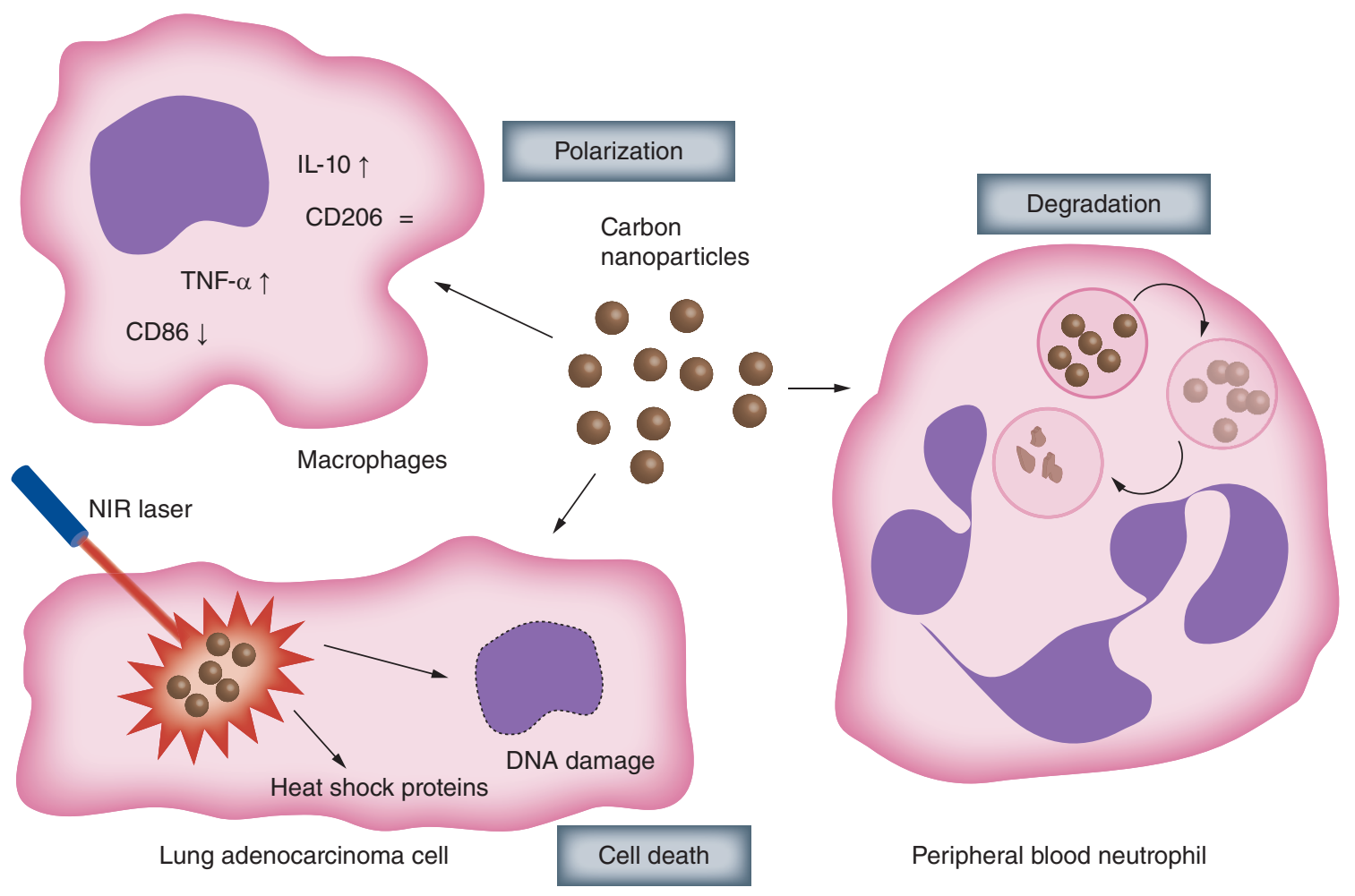

Figure 8. Near infrared-activated carbon nanoparticles induced cell death in human lung cancer cells and interacted in a reciprocal manner with human immune cells. Hence, carbon nanoparticles affected macrophage polarization, while carbon nanoparticles were 'digested' by peripheral blood neutrophils.

NIR: Near infrared.

finding in mouse macrophages [18]. Moreover, as shown in Figure 7D and Supplementary Figure 8A, CD86 (an M1 marker) was significantly downregulated after exposure at $20 \mu \mathrm{g} / \mathrm{ml}$ and $40 \mu \mathrm{g} / \mathrm{ml}$ of CNPs. On the other hand, CD206, an M2 marker, did not undergo any changes in surface expression (Figure 7E \& Supplementary Figure 8B). Furthermore, IL-10, characteristic of M2 polarization of macrophages, was upregulated following exposure to CNPs at $20 \mu \mathrm{g} / \mathrm{ml}$ (Figure 7F).

Finally, to exclude that any of the effects of CNPs on PMNs or HMDMs were due to endotoxin contamination, we evaluated the endotoxin content using the TNF- $\alpha$ expression test [30]. In this case, HMDMs were exposed to CNPs in the presence or absence of the endotoxin inhibitor polymyxin B sulphate $(10 \mathrm{mM})$, and LPS $0.1 \mu \mathrm{g} / \mathrm{ml}$ was included as a positive control. From these results (Supplementary Figure 8C), we noted that CNP-induced TNF- $\alpha$ secretion was not affected by the LPS inhibitor, polymyxin B, whereas LPS-induced TNF- $\alpha$ secretion was blocked by polymyxin B. We therefore concluded that the CNPs were endotoxin-free.

\section{Discussion}

Polysaccharide-derived CNPs have been shown to be very promising platforms for novel anticancer agents [22]. Recently, we developed glucose-derived graphitic CNPs that may overcome some of the limitations of other CNMs [18]. CNPs can be produced by a green synthesis in high yield, with low batch-to-batch variability. They exhibit antioxidant properties in vitro [18]. Furthermore, we have previously found that CNPs activated by NIR light generate singlet oxygen and heat, suggesting a possible application as dual photothermal/photodynamic agents for the therapy of solid tumors. Here we report for the first time that CNPs can efficiently induce the death of human lung cancer cells when activated by NIR light. This effect was related to the photothermal activity of CNPs, while a photodynamic effect was not evident. Importantly, CNPs were shown to be biocompatible in studies using human macrophages and we also documented neutrophil-driven biodegradation of CNPs. The findings are summarized in Figure 8.

Highly stable colloidal formulations composed of monodisperse CNPs have been prepared at hundred-gram scale. The reproducibility of the synthesis and the low batch-to-batch variability [18] indicate that CNPs can fulfill the 
standards required for pharmaceutical products and medical devices. The high colloidal stability and the negative surface of the particles were a consequence of the presence of acidic carboxylic groups exposed at the surface, as revealed by FTIR spectroscopy. Sterilization of the CNPs was performed without any modification of the internal or external structure, and the CNPs formed stable suspensions in cell culture media and were shown to be endotoxin free, an important prerequisite when assessing the interaction of nanoparticles with immune-competent cells [37]. Although a decrease of $\zeta$-potential was detected, as a consequence of the formation of a protein corona, no substantial agglomeration was observed, likely because of a stabilizing effect of adsorbed serum proteins by steric hindrance. This effect was similar to our previous observations in human plasma and blood [23]. Taken together, these results suggest that CNPs possess several desirable properties, including colloidal stability in relevant media. Note, however, that the formation of a protein corona in vivo may influence the pharmacokinetics of nanoparticles and this, therefore, is a topic that requires further exploration in animal models [38]. Even though the CNPs were not functionalized with any targeting agent, they were efficiently internalized by A549 cells and stored as CNP clusters in endosomes. No particles were found in the cell nucleus. However, CNPs may, in principle, come into contact with the nucleus during cell division, an aspect that deserves further investigation.

Nonactivated CNPs did not induce significant LDH release in lung adenocarcinoma A549 and NCI-H1650 cells or in human bronchial epithelial BEAS-2B cells up to $160 \mu \mathrm{g} / \mathrm{ml}$, in line with the absence of any abnormal ultrastructural features, as inferred by TEM measurements; on the contrary, when activated by NIR laser beam, CNPs induced cell death in A549 cells, as indicated by a dramatic change in cell morphology. The cytotoxic effect appeared to be related to the photothermal properties of CNPs. In fact, activated CNPs increased the temperature close to $50^{\circ} \mathrm{C}$, a value sufficient to induce cell death, in agreement with previous findings by other investigators [22]. This increase in temperature is consistent with the strong structural damage and loss of cell density observed in our model. On the other hand, singlet oxygen released by CNPs [18] appeared to have a minor role in the cytotoxic effect induced by activated CNPs. In fact, we did not detect a significant increase in ROS, nor in HNE adducts, suggesting that the oxidative stress is a secondary mechanism in NIR-activated CNP-induced cell death, or that the intrinsic scavenging properties of the CNPs toward hydroxyl radicals [18] are enough to buffer the oxidative stress, thus confirming what has previously been found in activated macrophages [18]. HSP overproduction is a typical cell survival mechanism involved in the response of cancer cells to PTT [39] and PDT [40,41] conferring to cancer cells resistance toward physical stresses. Overexpression of HSP has been observed in PTT induced by gold nanoparticles [39], single-walled carbon nanotubes [42] and graphene oxide [43]. High HSP expression (HSP70, HSP27) not only helps treated cells to handle heat- and ROS-induced damage, such as unfolded or irreversibly oxidized proteins, but also promotes cancer cell survival by preventing programmed cell death [34] and upregulating antioxidant enzymes such as glutathione peroxidase and glutathione reductase [44]. On the other hand, when released by tumor cells or bound at the cell membrane, HSPs (especially HSP70) are able to promote antitumor immunity [45]. In our experimental conditions, the increase in HSP70 and HSP90 was associated with limited signs of oxidative stress but a pronounced degree of cell death. The increase in HSP70 and HSP90, together with the antioxidant properties of CNPs [18], may explain why we observed only low signs of oxidative damage, as indicated by the slight increase in HNE-protein adducts. On the other hand, the high decrease of cell density indicated that the increase in HSP70 and HSP90 represented a compensatory, albeit unsuccessful, attempt of irradiated cells to prevent lethal damage. The high concentration of ROS induced by photothermal/photodynamic agents has been shown to produce DNA double strand breaks [46], a process that can be repaired by homologous [47] and nonhomologous [48] recombination enzymatic machineries. Phospho- $\gamma-\mathrm{H} 2 \mathrm{AX}$ histone is a recruiter of the DNA repair complex; each focus of phospho- $\gamma-\mathrm{H} 2 \mathrm{AX}$ corresponds to a site of DNA damage [49]. The pattern of phospho$\gamma$-H2AX observed in our experimental conditions may be the result of a thermal denaturation of DNA that causes irreversible damage, although a contribution of particle-derived singlet oxygen cannot be excluded. Moreover, if DNA lesions are repaired, $\gamma$-H2AX foci are disassembled and H2AX is dephosphorylated [50]; otherwise, lethal DNA damage and cell death will ensue [51]. Thus the presence of unresolved $\gamma-\mathrm{H} 2 \mathrm{AX}$ foci in tumor cells $24 \mathrm{~h}$ after treatment, as shown here, strongly suggests irreversible DNA damage of the cells. In summary, we provide evidence for a strong anticancer effect of NIR-activated CNPs in a model of NSCLC, characterized by an elevation of HSPs and the induction of DNA lesions.

Biocompatibility is a critical issue in nanomedicine. Importantly, we found that no cytotoxicity occurred in primary human macrophages at doses up to $80 \mu \mathrm{g} / \mathrm{ml}$. This suggests a good biocompatibility of CNPs and confirms our previous findings using the murine RAW 264.7 macrophage-like cell line [18]. However, a modest loss of cell viability was noted in PMNs. Coupled with (short-term) biocompatibility is the issue of long-term 
biopersistence. The latter is related to a possible accumulation of nanomaterials in the body, which could lead to adverse effects on human health; therefore the investigation of the degradability of CNMs is a crucial aspect of their safety assessment [52]. In the last decade, several studies have evidenced the role and efficacy of neutrophil-derived MPO in the biodegradation of CNTs [53], fullerenes [54], graphene oxide [27] and single- and few-layer graphene [55]. Different mechanisms of degradation have been proposed. In particular, in the presence of hydrogen peroxide, MPO is able to oxidize chloride ions to form hypochlorous acid [56], a strong oxidant compound which contributes to the biodegradation of CNMs together with the reactive radical intermediates produced by the enzyme [53]. Indeed, Newman et al. reported that hypochlorite alone could 'digest' a variety of different CNMs [57]. Several other oxidants, like hydrogen peroxide [58], hydroxyl radicals [59] and peroxynitrite [60], were found to oxidize and degrade CNMs. However, the susceptibility of CNMs to degradation is largely dependent upon the kind of CNM, its crystallinity and degree of functionalization. In general, interruptions of the conjugated $\pi-\pi$ lattice (defects) are more susceptible to free radicals and oxidant attack [61]. Here we demonstrate for the first time that CNPs are degraded by MPO in an acellular setting and following incubation with freshly isolated PMNs. Notably, we found that degradation occurs without prior activation of the cells, suggesting that CNPs themselves are capable of inducing degranulation of PMNs with sufficient release of MPO to allow for subsequent degradation. CNPs were also susceptible to degradation by $\mathrm{NaClO}$ alone, while they appeared resistant to $\mathrm{H}_{2} \mathrm{O}_{2}$.

Macrophages undergo phenotypic changes in response to extracellular signals through a process of polarization, which plays a key role in the tumor-infiltrating immune cells. Indeed, it is well known that tumor-associated macrophages are the key regulators of the immune response toward solid tumors [62]. We recently reported that another type of CNM, so-called nanodiamonds, can induce macrophage polarization in pancreatic adenocarcinomas in mice with a reduction in IL-10 cytokine expression [63]. In the present study we found that CNPs elicited a significantly reduced level of CD86, a marker of M1 polarization, without affecting CD206, a marker of M2 polarization. Furthermore, CNPs induced the release of both IL-10 and TNF- $\alpha$, resulting in a mixed M1/M2 phenotype, albeit in the absence of cell death. Further studies in relevant animal models are required to assess whether CNPs affect tumor-associated macrophages.

\section{Conclusion}

The present study has shown that CNPs exhibit strong NIR-induced phototoxicity toward A549 lung cancer cells. The effect appears mainly related to the photothermal properties of CNPs. In addition, nonactivated CNPs exhibited an excellent safety profile toward primary human immune cells. We also provided evidence for the biodegradation of CNPs by recombinant MPO, and this was confirmed in ex vivo cultivated human neutrophils. The latter observations are important, as they suggest that bioaccumulation of CNPs may be avoided, hence reducing unwanted long-term effects. Finally, CNPs modulate macrophage polarization, an observation that deserves further investigation. Overall, the in vitro data reported herein reveal fundamental aspects of the behavior of CNPs in the tumor microenvironment that may accelerate their possible clinical translation as agents for hyperthermia or as enhancers of tumor ablation. Next, studies using relevant animal models are needed.

\section{Future perspective}

Laser ablation is one of the most advanced modalities currently utilized to treat solid tumors. CNPs may be harnessed for laser ablation, allowing a more precise delivery of the heat. In perspective, the use of appropriate targeting agents might increase the ability of these nanoparticles to accumulate in cancer cells, thus increasing the efficacy against tumor cells and preserving healthy tissues.

\section{Summary points}

- Carbon nanoparticles (CNPs) possessing photothermal properties were synthesized through a hydrothermal route.

- Near-infrared light-activated CNPs induced cell death in human lung adenocarcinoma cells.

- CNPs affected the polarization of primary human macrophages without signs of cytotoxicity.

- CNPs elicited a modest cytotoxicity toward primary human neutrophils when tested ex vivo.

- CNPs were biodegraded by recombinant myeloperoxidase and by primary human neutrophils.

- In summary, CNPs are identified as promising platforms for photothermal lung cancer therapy. 


\section{Supplementary data}

To view the supplementary data that accompany this paper please visit the journal website at: www.futuremedicine.com/doi/sup $\mathrm{pl} / 10.2217 / \mathrm{nnm}-2021-0009$

\section{Author contributions}

I Kokalari was responsible for the methodology and investigation and writing of the original draft. S Keshavan, M Rahman and E Gazzano were responsible for the methodology and investigation. G Barzan, L Mandrile, J Ponti and G Antonello were responsible for the investigation. A Giovannozzi was responsible for supervision. M Monopoli and E Bergamaschi were responsible for resources. G Perrone and C Riganti were responsible for supervision and resources. B Fadeel was responsible for supervision and resources, and writing, review and editing of the manuscript. I Fenoglio was responsible for conceptualization and supervision, and writing, review and editing of the manuscript.

\section{Acknowledgments}

Cellular TEM data were achieved through access to the Nanobiotechnology Laboratory under the Framework for open access to the Joint Research Centre Research Infrastructures of the European Commission.

Financial \& competing interests disclosure

Supported by the European Commission through the H2020 project BIORIMA (grant agreement no. 760928). I Kokalari received a PhD award from Ministero dell'Istruzione dell'Universitàe della Ricerca (MIUR). The authors have no other relevant affiliations or financial involvement with any organization or entity with a financial interest in or financial conflict with the subject matter or materials discussed in the manuscript apart from those disclosed.

No writing assistance was utilized in the production of this manuscript.

\section{Ethical conduct of research}

The authors state that they have obtained appropriate institutional review board approval or have followed the principles outlined in the Declaration of Helsinki for all human or animal experimental investigations.

\section{Open access}

This work is licensed under the Attribution-NonCommercial-NoDerivatives 4.0 Unported License. To view a copy of this license, visit http://creativecommons.org/licenses/by-nc-nd/4.0/

\section{References}

Papers of special note have been highlighted as: • of interest; $\bullet \bullet$ of considerable interest

1. Sung H, Ferlay J, Siegel RL et al. Global Cancer Statistics 2020: GLOBOCAN estimates of incidence and mortality worldwide for 36 cancers in 185 countries. CA Cancer J. Clin. doi:10.3322/caac.21660 (2021) (Epub ahead of print).

2. Alexander M, Kim SY, Cheng H. Update 2020: management of non-small-cell lung cancer. Lung 198, 897-907 (2020).

3. Lang-Lazdunski L. Surgery for non-small-cell lung cancer. Eur. Respir. Rev. 22(129), 382-404 (2013).

4. Huynh C, Walsh LA, Spicer JD. Surgery after neoadjuvant immunotherapy in patients with resectable non-small-cell lung cancer. Transl. Lung Cancer Res. 10(1), 563-580 (2021).

5. Sosa Iglesias V, Giuranno L, Dubois LJ, Theys J, Vooijs M. Drug resistance in non-small-cell lung cancer: a potential for NOTCH targeting? Front. Oncol. 8, 267 (2018).

6. Zhang Y, Zhou L, Tan J, Liu J, Shan X, Ma Y. Laser-triggered collaborative chemophotothermal effect of gold nanoparticles for targeted colon cancer therapy. Biomed. Pharmacother. 130, 110492 (2020).

7. Zhang Y, Wan Y, Chen Y, Blum NT, Lin J, Huang P. Ultrasound-enhanced chemo-photodynamic combination therapy by using albumin 'nanoglue'-based nanotheranostics. ACS Nano 14(5), 5560-5569 (2020).

8. Sheth RA, Wen X, Li J et al. Doxorubicin-loaded hollow gold nanospheres for dual photothermal ablation and chemoembolization therapy. Cancer Nanotechnol. 11, 6 (2020).

9. Yano S, Naemura M, Toshimitsu A et al. Efficient singlet oxygen generation from sugar pendant C60 derivatives for photodynamic therapy. Chem. Commun. 51(93), 16605-16608 (2015).

10. Jayadevappa R, Chhatre S, Soukiasian HJ, Murgu S. Outcomes of patients with advanced non-small-cell lung cancer and airway obstruction treated with photodynamic therapy and non-photodynamic therapy ablation modalities. J. Thorac. Dis. 11(10), 4389-4399 (2019).

11. Shafirstein G, Battoo A, Harris K et al. Photodynamic therapy of non-small-cell lung cancer. Narrative review and future directions. Ann. Am. Thorac. Soc. 13(2), 265-275 (2016). 
12. Zhou F, Xing D, Ou Z, Wu B, Resasco DE, Chen WR. Cancer photothermal therapy in the near-infrared region by using single-walled carbon nanotubes. J. Biomed. Opt. 14(2), 021009 (2009).

13. Robinson JT, Welsher K, Tabakman SM et al. Performance in vivo near-IR (>1 mum) imaging and photothermal cancer therapy with carbon nanotubes. Nano. Res. 3(11), 779-793 (2010).

14. Serda M, Szewczyk G, Krzysztyńska-Kuleta O et al. Developing [60]fullerene nanomaterials for better photodynamic treatment of non-melanoma skin cancers. ACS Biomater. Sci. Eng. 6(10), 5930-5940 (2020).

15. Liu J, Yuan X, Deng L et al. Graphene oxide activated by $980 \mathrm{~nm}$ laser for cascading two-photon photodynamic therapy and photothermal therapy against breast cancer. Appl. Mater. Today 20, 100665 (2020).

16. Bhattacharya K, Mukherjee SP, Gallud A et al. Biological interactions of carbon-based nanomaterials: from coronation to degradation. Nanomedicine 12(2), 333-351 (2016).

- Comprehensive review of carbon-based materials in medicine.

17. Zhang P, Qiaoa Z, Dai S. Recent advances in carbon nanospheres: synthetic routes and applications. Chem. Commun. 51, 9246-9256 (2015).

18. Kokalari I, Gassino R, Giovannozzi AM et al. Pro- and anti-oxidant properties of near-infrared (NIR) light responsive carbon nanoparticles. Free Radic. Biol. Med. 134, 165-176 (2019).

-• Carbon nanoparticles with well-defined properties are synthetized.

19. Selvi BR, Jagadeesan D, Suma BS et al. Intrinsically fluorescent carbon nanospheres as a nuclear targeting vector: delivery of membrane-impermeable molecule to modulate gene expression in vivo. Nano Lett. 8(10), 3182-3188 (2008).

20. Li N, Li T, Hu C, Lei X, Zuo Y, Han H. Targeted near-infrared fluorescent turn-on nanoprobe for activatable imaging and effective phototherapy of cancer cells. ACS Appl. Mater. Interfaces 8(24), 15013-15023 (2016).

21. Ajmal M, Yunus U, Matin A, Haq NU. Synthesis, characterization and in vitro evaluation of methotrexate conjugated fluorescent carbon nanoparticles as drug delivery system for human lung cancer targeting. J. Photochem. Photobiol. B 153, 111-120 (2015).

22. Miao ZH, Wang H, Yang H, Li Z, Zhen L, Xu CY. Glucose-derived carbonaceous nanospheres for photoacoustic imaging and photothermal therapy. ACS Appl. Mater. Interfaces 8(25), 15904-15910 (2016).

23. Soddu L, Trinh DN, Dunne E et al. Identification of physicochemical properties that modulate nanoparticle aggregation in blood. Beilstein J. Nanotechnol. 11, 550-567 (2020).

- Carbon nanoparticles are shown to be stable in human plasma.

24. Ossig R. Rösslein M. Detection of bacterial contamination by agar plate test. (2021). www.euncl.eu/about-us/assay-cascade/PDFs/Prescreening/EUNCL-STE-002_2.pdf?m=1476164583\&

25. Polimeni M, Gazzano E, Ghiazza M et al. Quartz inhibits glucose 6-phosphate dehydrogenase in murine alveolar macrophages. Chem. Res. Toxicol. 21(4), 888-894 (2008).

26. Gassino R, Kokalari I, Vallan A, Fenoglio I, Perrone G. A compact diode laser based all-fiber delivery system for PDT+PTT with integrated temperature sensing capabilities. In: The International Society for Optical Engineering. Chou TH, Kessel DH (Eds). SPIE, CA,USA (2017).

27. Mukherjee SP, Gliga AR, Lazzaretto B et al. Graphene oxide is degraded by neutrophils and the degradation products are non-genotoxic. Nanoscale 10(3), 1180-1188 (2018).

28. Gallud A, Bondarenko $\mathrm{O}$, Feliu $\mathrm{N}$ et al. Macrophage activation status determines the internalization of mesoporous silica particles of different sizes: exploring the role of different pattern recognition receptors. Biomaterials 121, 28-40 (2017).

29. Martín C, Ruiz A, Keshavan S et al. A biodegradable multifunctional graphene oxide platform for targeted cancer therapy. Adv. Funct. Mater. 29(39), 1901761 (2019).

30. Mukherjee SP, Lozano N, Kucki M et al. Detection of endotoxin contamination of graphene-based materials using the TNF- $\alpha$ expression test and guidelines for endotoxin-free graphene oxide production. PLoS ONE 11, 1-17 (2016).

31. Li M, Li W, Liu S. Hydrothermal synthesis, characterization, and $\mathrm{KOH}$ activation of carbon spheres from glucose. Carbohydr. Res. 346(8), 999-1004 (2011).

32. Qi Y, Zhang M, Qi L, Qi Y. Mechanism for the formation and growth of carbonaceous spheres from sucrose by hydrothermal carbonization. RSC Adv. 6(25), 20814-20823 (2016).

33. Gazzano E, Ghiazza M, Polimeni $M$ et al. Physicochemical determinants in the cellular responses to nanostructured amorphous silicas. Toxicol. Sci. 128(1), 158-170 (2012).

34. Richter K, Haslbeck M, Buchner J. The heat shock response: life on the verge of death. J. Mol. Cell 40, 253-266 (2010).

35. Postiglione I, Barra F, Aloj SM, Palumbo G. Photodynamic therapy with 5-aminolaevulinic acid and DNA damage: unravelling roles of p53 and ABCG2. Cell Prolif. 49(4), 523-538 (2016).

36. Keshavan S, Calligari P, Stella L, Fusco L, Delogu LG, Fadeel B. Nano-bio interactions: a neutrophil-centric view. Cell Death Dis. 10(8), 569 (2019) 
37. Andón FT, Mukherjee SP, Gessner I et al. Hollow carbon spheres trigger inflammasome-dependent IL-1 $\beta$ secretion in macrophages. Carbon. 113, 243-251 (2017).

38. Liu Y, Wang J, Xiong Q, Hornburg D, Tao W, Farokhzad OC. Nano-bio interactions in cancer: from therapeutics delivery to early detection. Acc. Chem. Res. 54, 291-301 (2021).

39. Abadeer NS, Murphy CJ. Recent progress in cancer thermal therapy using gold nanoparticles. J. Phys. Chem. C. 120(9), 4691-4716 (2016).

40. Rodriguez ME, Cogno IS, Milla Sanabria LS, Moran YS, Rivarola VA. Heat shock proteins in the context of photodynamic therapy: autophagy, apoptosis and immunogenic cell death. Photochem. Photobiol. Sci. 15(9), 1090-1102 (2016).

41. Liu C, Qin H, Kang L et al. Graphitic carbon nitride nanosheets as a multifunctional nanoplatform for photochemical internalization-enhanced photodynamic therapy. J. Mater. Chem. B 6(47), 7908-7915 (2018).

42. Yang J, Hou M, Sun W et al. Sequential PDT and PTT using dual-modal single-walled carbon nanohorns synergistically promote systemic immune responses against tumor metastasis and relapse. Adv. Sci. 7, 2001088 (2020).

43. Barrera CC, Groot H, Vargas WL, Narváez DM. Efficacy and molecular effects of a reduced graphene Oxide $/ \mathrm{Fe}_{3} \mathrm{O}_{4}$ nanocomposite in photothermal therapy against cancer. Int. J. Nanomed. 15, 6421-6432 (2020).

44. Guo S, Wharton W, Moseley P, Shi H. Heat shock protein 70 regulates cellular redox status by modulating glutathione-related enzyme activities. Cell Stress Chaperones 12(3), 245-254 (2007).

45. Calderwood SK, Ciocca DR. Heat shock proteins: stress proteins with Janus-like properties in cancer. Int. J. Hyperthermia 24(1), 31-39 (2008).

46. Wang M, Zhao $\mathrm{Y}$, Chang $\mathrm{M}$ et al. Azo initiator loaded black mesoporous titania with multiple optical energy conversion for synergetic photo-thermal-dynamic therapy. ACS Appl. Mater. Interfaces 11(51), 47730-47738 (2019).

47. Wright WD, Shah SS, Heyer WD. Homologous recombination and the repair of DNA double-strand breaks. J. Biol. Chem. 293(27), 10524-10535 (2018).

48. Pannunzio NR, Watanabe G, Lieber MR. Nonhomologous DNA end-joining for repair of DNA double-strand breaks. J. Biol. Chem. 293(27), 10512-10523 (2018).

49. Kuo LJ, Yang LX. Gamma-H2AX - a novel biomarker for DNA double-strand breaks. In Vivo 22(3), 305-309 (2008).

50. Cobler L, Zhang H, Suri P, Park C, Timmerman LA. CT inhibition sensitizes tumors to gamma-radiation via glutathione reduction. Oncotarget 9(64), 32280-32297 (2018).

51. Banath JP, Klokov D, MacPhail SH, Banuelos CA, Olive PL. Residual gammaH2AX foci as an indication of lethal DNA lesions. BMC Cancer 10, 4 (2010).

52. Vlasova II, Kapralov AA, Michael ZP et al. Enzymatic oxidative biodegradation of nanoparticles: mechanisms, significance and applications. Toxicol. Appl. Pharmacol. 299, 58-69 (2016).

- The mechanism of degradation of nanoparticles is discussed.

53. Kagan VE, Konduru NV, Feng W et al. Carbon nanotubes degraded by neutrophil myeloperoxidase induce less pulmonary inflammation. Nat. Nanotechnol. 5(5), 354-359 (2010).

-. The ability of myeloperoxidase to degrade carbon nanotubes is reported.

54. Litasova EV, Iljin VV, Sokolov AV, Vasilyev VB, Dumpis MA, Piotrovskiy LB. The biodegradation of fullerene C60 by myeloperoxidase. Dokl. Biochem. Biophys. 471(1), 417-420 (2016).

55. Kurapati R, Mukherjee SP, Martin C et al. Degradation of single-layer and few-layer graphene by neutrophil myeloperoxidase. Angew. Chem. Int. Ed. Engl. 57(36), 11722-11727 (2018).

56. Hampton MB, Kettle AJ, Winterbourn CC. Inside the neutrophil phagosome: oxidants, myeloperoxidase, and bacterial killing. Blood 92(9), 3007-3017 (1998).

57. Newman L, Lozano N, Zhang M et al. Hypochlorite degrades 2D graphene oxide sheets faster than $1 \mathrm{D}$ oxidised carbon nanotubes and nanohorns. NPJ 2D Mater. Appl. 1(1), 39 (2017).

58. Xing WL, Lalwani G, Rusakova I, Sitharaman B. Degradation of graphene by hydrogen peroxide. Part. Part. Syst. Char. 31(7), 745-750 (2014).

59. Bai H, Jiang W, Kotchey GP et al. Insight into the mechanism of graphene oxide degradation via the photo-Fenton reaction. J. Phys. Chem. C 118(19), 10519-10529 (2014).

60. Bhattacharya K, Sacchetti C, Costa PM et al. Nitric oxide dependent degradation of polyethylene glycol-modified single-walled carbon nanotubes: implications for intra-articular delivery. Adv. Healthc. Mater. 7(6), e1700916 (2018).

61. Ghiazza M, Vietti G, Fenoglio I. Carbon Nanotubes: Properties, Applications, and Toxicity. Woodhead Publishing, Cambridge, UK (2014).

62. Noy R, Pollard JW. Tumor-associated macrophages: from mechanisms to therapy. Immunity 41, 49-61 (2014).

63. Madamsetty VS, Pal K, Keshavan S et al. Development of multi-drug loaded PEGylated nanodiamonds to inhibit tumor growth and metastasis in genetically engineered mouse models of pancreatic cancer. Nanoscale 11(45), 22006-22018 (2019).

- The ability of nanodiamonds to induce polarization of macrophages is shown. 